\title{
A Deterministic Approach to Earthquake Prediction
}

\author{
Vittorio Sgrigna $^{1}$ and Livio Conti ${ }^{2}$ \\ ${ }^{1}$ Dipartimento di Fisica and Sezione INFN, Università Roma Tre, 84 Via della Vasca Navale, 00146 Roma, Italy \\ ${ }^{2}$ Facoltà di Ingegneria, Università Telematica Internazionale UNINETTUNO, Corso Vittorio Emanuele II 39, 00186 Roma, Italy
}

Correspondence should be addressed to Livio Conti, conti.livio@gmail.com

Received 14 July 2011; Revised 27 January 2012; Accepted 6 February 2012

Academic Editor: Yamaoka Koshun

Copyright ( 2012 V. Sgrigna and L. Conti. This is an open access article distributed under the Creative Commons Attribution License, which permits unrestricted use, distribution, and reproduction in any medium, provided the original work is properly cited.

The paper aims at giving suggestions for a deterministic approach to investigate possible earthquake prediction and warning. A fundamental contribution can come by observations and physical modeling of earthquake precursors aiming at seeing in perspective the phenomenon earthquake within the framework of a unified theory able to explain the causes of its genesis, and the dynamics, rheology, and microphysics of its preparation, occurrence, postseismic relaxation, and interseismic phases. Studies based on combined ground and space observations of earthquake precursors are essential to address the issue. Unfortunately, up to now, what is lacking is the demonstration of a causal relationship (with explained physical processes and looking for a correlation) between data gathered simultaneously and continuously by space observations and ground-based measurements. In doing this, modern and/or new methods and technologies have to be adopted to try to solve the problem. Coordinated space- and groundbased observations imply available test sites on the Earth surface to correlate ground data, collected by appropriate networks of instruments, with space ones detected on board of Low-Earth-Orbit (LEO) satellites. Moreover, a new strong theoretical scientific effort is necessary to try to understand the physics of the earthquake.

\section{Introduction}

In our opinion, the investigation of possible earthquake prediction must be carried out on a deterministic basis. Unfortunately, at the moment, the study of the physical conditions that give rise to an earthquake and the processes that precede a seismic rupture of an ordinary event are at a very preliminary stage and, consequently, the techniques of prediction of time of origin, epicentre, and magnitude of an impending earthquake now available are below standard.

Therefore, the present level of knowledge is unable to achieve the objective of a deterministic prediction of an ordinary seismic event, but it certainly will in a more or less distant future tackle the problem with seriousness and avoiding scientifically incorrect, wasteful, and inconclusive shortcuts, as sometimes has been done. It will take long time (may be years, tens of years, or centuries) because this approach requires a great cultural, financial, and organizational effort on an international basis. It implies the need for carrying out combined ground and near-Earth space continuous observations of the so-called earthquake precursors, coseismic and postseismic phenomena, as well as the development of appropriate theoretical models able to justify the observations in order to understand the physical mechanisms underlying the earthquake preparation and occurrence. So, ground networks of instruments in the major seismic areas of the Earth and Low-Earth-orbit (LEO) multiinstrument satellites, as well as laboratory and theoretical investigations, will be necessary to address the study carried out by coordinate teams of researchers and specialists in the different scientific and technical fields of the physics of the Earth system. Probably, the pressure of act more quickly sometimes gives bad advise. An example of such behaviour has been given even on the occasion of the recent destructive seismic event occurred in Japan last March 2011 when, also inside groups of the scientific community, reckless statements were raised hinting the hypothesis (and someone has actually said) that earthquake prediction is possible, especially if it is possible there will be financial support and some kind of scientific coordination. 
Remember that the 2011 March 11 05:46:23 UTC Tohoku earthquake (near the East coast of Honshu, Japan), also knows as the Great East Japan Earthquake, had magnitude 9.0; location $38.322^{\circ} \mathrm{N}, 142.369^{\circ} \mathrm{E}$; depth $32 \mathrm{~km}$. It was the Japan's most powerful earthquake since records began and has struck the north-east coast, triggering a massive tsunami. The Japanese National Police Agency has confirmed 15.550 deaths, 5.688 injured, and 5.344 people missing across twenty-tow prefectures, as well as about 225.000 buildings damaged or destroyed [1].

In the face of such huge disaster, the above-mentioned claims on the earthquake prediction must be considered as regrettable. They were issued through mass media and even within a pseudoscientific context, and appearing as a kind of "scientific looting." Such false statements can only be used to take advantage of the disaster, maybe to obtain more easily research funds or for a greater visibility within the scientific community, civil services, and authorities that need to take adequate measures for assistance and protection of the population and reconstruction of houses and infrastructures. To justify the concept of earthquake prediction, "noises" are often introduced thus confusing different concepts such as earthquake precursor, seismic hazard, earthquake warning, and earthquake forecasting. A similar disgraceful behaviour does not produce any result useful to science or to society.

This "vulnus" inside the scientific community cannot easily be healed and overcame, since mediocre minds are as able to organize themselves as brilliant ones. So, selfreferential poor groups of researchers are easily formed and can also permeate international peer-review systems.

But any honest scientist knows that the way to go is almost always one more long and tiring. It requires intelligence, time, perseverance, and scientific humility and honesty.

As mentioned above, a possible contribution to a deterministic earthquake prediction approach may be given by observations and physical modelling of earthquake precursors aimed at seeing, in perspective, the earthquake phenomenon within the framework of a unified theory able to explain the causes of its genesis, and the dynamics, rheology, and microphysics of its preparation, occurrence, postseismic relaxation, and interseismic phases. Unfortunately, up to now what is lacking is the demonstration of a causal relationship (with explained physical processes and looking for a correlation) between data gathered simultaneously and continuously by space observations and ground-based measurements. In doing this, modern and/or new methods and technologies have to be adopted to try to solve the problem.

Within this framework, a few projects and experiments have been carried out on the subject by our team and accompanied by specific theoretical interpretations. They are reported in the paper. As an introduction and justification to these studies and also to avoid confusion, we try to clarify some basic concepts on the matter, critical and methodological aspects concerning deterministic and statistic approaches, and their use in earthquake prediction and warning.

The earthquake prediction and damage prevention methods, as well as the analysis of lithosphere-atmosphere couplings associated with the preparation of seismic events, are the introductory and basic elements of the paper. They will be discussed in this section.

\subsection{Earthquake Damage Prevention and Deterministic Pre-} diction Concepts. It is well known that earthquakes are a manifestation of significant ground rock deformation events, that is, episodic deformations of the upper and, more or less, brittle layers of the Earth's lithosphere. These can be classified as fast seismic ruptures, slow earthquakes, and subseismic events. Since the energy released during large earthquakes affects human life, the development and application of appropriate and efficient techniques to defend society from these destructive effects are necessary. At the present time, only two suitable approaches are available: damage prevention and prediction methods.

Earthquake damage prevention implies the development of methods for evaluating seismic risks in order to enable disaster assessment and techniques for use in estimating seismic risk, with the ultimate aim of reducing damage produced by earthquakes through reliable means. The prevention of damage is achievable with existing state of knowledge. In this approach, a great importance lies in the optimization of methods necessary to determine the three main factorsvulnerability, value, and hazard - which define seismic risk.

In contrast, the deterministic prediction of the time of origin, hypocentral (or epicentral) location, and magnitude of an impending earthquake is an open scientific problem. The reason for this is that such predictions are based on the detection of the so-called earthquake precursors or preearthquake phenomena, and the physical interpretation of these is a very complicated matter.

At this point, a few main concepts on precursor detectability must be considered. First, it must be clear that reducing "physics of the earthquake" only to the creation of fault rupture and consequent seismic wave propagation is to oversimplify the problem. In fact, it has been repeatedly observed that part of the accumulated (preseismic) elastic energy is also converted to other kind of energies (electromagnetic, acoustic, heat, etc.) and that these conversion mechanisms are probably similar to that of seismic energy. Moreover, observations during interseismic and preseismic periods indicate that large earthquakes are often preceded by signals of different natures (the so-called earthquake precursors), of which the mechanical (tilt and strain), gaseous (helium and radon), and electromagnetic ones have been demonstrated to be the most significant manifestations (see this paper and also [2]). However, the study of the physical conditions that give rise to an earthquake and of the processes that precede a seismic rupture is at a very preliminary stage and, consequently, the techniques of prediction available at the moment are below standard.

In trying to by-pass these difficulties, many investigators have likely been attracted by a statistical prediction approach based on the so-called earthquake forecasting method, that is, the probability of occurrence of an event in a given geographical location, within assigned values of magnitude and time ranges. However, even though the forecasting 
methods, such as those of the M8 and $\mathrm{CN}$ algorithms (e.g., [3-5]) or of the acceleration deformation approach (e.g., [6]) have reached a very good level of maturity and can display a good level of importance and practical use, they overlap with the seismic hazard concept, one of the three factors used to estimate seismic risk. This could result in a possible ambiguity in the application of earthquake prediction and earthquake damage prevention approaches, which could give rise to a kind of "methodological noise" that would be capable of introducing systematic errors in the use of the two methods. We, therefore, believe that it should be better to pursue the deterministic prediction approach even if a reliable deterministic method of earthquake prediction will presumably be available only in the more distant future.

This conclusion is also confirmed by the underestimated expectation of earthquake prediction in a relatively short period of time based on the basis of seismic precursor studies carried out in the last decades. As mentioned above, the physics of earthquakes has been demonstrated to be a very complicated matter. Nevertheless, research with this aim continues with a critical view, new ideas, and thorough investigations, and the results seem to be promising. Therefore, we propose to carry out studies based on the physics of earthquake precursors, including the necessary field measurements in seismic areas and appropriate laboratory and theoretical investigations to corroborate the observations.

Progress in this area could be due not only to increased amounts and accuracy of ground field measurements, careful attention to errors in data, and improved understanding of earthquake source mechanics, but also-and possibly most importantly - to a new approach based on observations from space.

But how to reach a deterministic seismic prediction by earthquake precursors needs to be better clarified since it is considered by several authors that such an approach seems to be unadvisable because for a deterministic prediction the space localization (epicentre or hypocenter), the time of origin, and the energy or magnitude of an impending earthquake are required at the same time. A possible method on how in principle to practically predict earthquakes with precursory phenomena is proposed at the beginning of Section 3.

\subsection{Seismoelectromagnetic Emissions and Couplings between} Solid Earth and Near-Earth Space. A great contribution for constructing a deterministic prediction model arises by preearthquake (or precursory) phenomena, since they may help in understanding the physical mechanisms underlying the preparation phase of a seismic event. It has been shown that in the Earth's crust, rock microfracturing preceding a seismic rupture may cause local surface deformation fields, rock dislocations, charged particle generation and motion, electrical conductivity changes, gas emission, fluid diffusion, electrokinetic (EKE), piezomagnetic, and piezoelectric effects. It has also been proposed that charge carriers could be activated in dry rocks mainly by the increasing external stress. These mechanisms have been considered as the main sources of the so-called seismoelectromagnetic emissions (SEME) consisting of broad-band (from DC to a few tens of $\mathrm{MHz}$ ) electromagnetic (EM) fields observed at the Earth's surface and in the near-Earth space (neutral and ionised atmosphere and magnetosphere). Electromagnetic emissions (EMEs) radiated from the Earth's surface and produced as a consequence of earthquake preparation and occurrence, or by human activities, demonstrated to propagate through the near-Earth space and to cause perturbations of electric and magnetic fields and Van Allen radiation belt particle precipitations, ionospheric variations of temperature and density of the ionic, and electronic plasma components in the topside ionosphere. These perturbations are detectable by Low-Earth-Orbit (LEO) satellites [2, 7-9].

Within this framework, natural disasters, such as earthquakes, and the impact of anthropogenic EME waves (power line harmonic radiation, VLF transmitters, HF broadcasting stations) in the near-Earth space can also be considered as coupling elements of the lithosphere-atmosphereionosphere-magnetosphere interactions. All above mentioned suggests that to better investigate the phenomenon earthquake, simultaneous and coordinated space and ground-based observations in seismic areas have to be carried out. The main problem in this studies is to reconcile near-Earth space perturbations only with the propagation of SEME-waves through the atmosphere and magnetosphere, filtering from the data the impact of atmospheric EME waves during thunderstorm activity, and effects of sun and cosmic rays in the geomagnetic cavity.

Space observations are being performed or are going to be carried out, in the ionosphere-magnetosphere transition region, and a few satellite missions (Demeter, QuakeSat, Sich-1 M, Compass-1/2, Esperia, Egle, Arina, Ausonia, etc.) have already been carried out and/or are proposed from 2001 until the present $[2,10-15]$.

The basic premise is that observations of different ground and space seismic precursors as well as laboratory experiments on rocks and the development of theoretical models, all of which aimed at placing the phenomenon "earthquake" within the framework of a unified theory, would be able to explain the causes of its genesis, and the dynamics, rheology, and microphysics of its preparation, occurrence, postseismic relaxation and interseismic phases. The physical system to be considered includes solid Earth and nearEarth space with related couplings and perturbations. Also, it is hoped that a better scientific coordination on an international basis between diverse teams of researchers would smooth out and integrate different methodological approaches relatively to each other for a better use of the different competences, instruments, and databases. Up to now what is lacking is the demonstration of a causal relationship with explained physical processes and looking for a correlation between data gathered simultaneously and continuously by space observations and ground-based measurements. That is why we believe that the best approach is to plan and design coordinated and simultaneous ground-based measurements (carried out by appropriate networks of instruments in available test sites on the Earth surface) to be correlated with multiparametric space observations onboard satellites, 
together with the development of appropriate methods of data analysis and theoretical modeling. To this end, we have installed the TELLUS tilt network in the seismic area of the Central Apennines of Italy. This network will, in the near future, also include magnetometers and specific devices to detect electric field. Results obtained by the TELLUS network have been reported [16]. Within the framework of a guest investigation programme we have studied data collected in the topside ionosphere by the DEMETER microsatellite, proposed a specific LEO satellite project (ESPERIA) and built and tested in space two ESPERIA instruments (the EGLE magnetometer and ARINA particle detector). At the same time, we also have made first attempts to develop a theoretical model of the genesis and propagation of preearthquake electromagnetic emissions in the lithosphere and near-Earth space [7, 15, 17-19].

In 2007, after an IUGG resolution in support of ESPERIA (2007 IUGG resolution number 5) for an ionospheric space mission, we submitted to the Italian Space Agency (ASI) a new space project (AUSONIA), with more large scientific objectives than those of ESPERIA. AUSONIA includes the monitoring and mapping of the ionosphere and of the Earth magnetic field and also the study of tropospheric transient emissions [14]. Then, AUSONIA can investigate both perturbative and steady-state phenomena.

Next two sections will clarify basic concepts concerning hypocentral focal zone and epicentral precursory area (Section 2) and refer to reliable results reported in literature about earthquake precursors (Section 3 ) and their possible use as seismic predictors. The following Sections 4-5 report the ESPERIA and AUSONIA space mission projects and the description and testing of the first ESPERIA and AUSONIA instruments: the EGLE magnetometer and ARINA particle detector.

\section{Hypocentral Preparation Focal Zone and Epicentral Precursory Area}

The most familiar brittle lithospheric deformation event is defined as ordinary earthquake, that is, a deformation, fracture, structure, and phase transformation phenomenon, which releases suddenly a large amount of the elastic energy stored in the medium and is accompanied by a substantial fraction of energy radiated as elastic (seismic) waves. Seismic wave energy is a certain part (from about 1 to $10 \%$ ) of total (radiated and not radiated) energy, and it is usually assumed as an estimate of the total energy of the earthquake. Moderate and strong earthquakes, with magnitude from 5.0 to 9.0, have energy and seismic moment [20] approximately in the range $10^{12}-10^{18} \mathrm{~J}$ and $10^{17}-10^{22} \mathrm{Nm}$, respectively, as given by the following well-known relationships (in cgs units) between energy $(E)$, scalar seismic moment $\left(M_{0}\right)$, and surface earthquake magnitude $\left(M_{S}\right)$ :

$$
\begin{aligned}
\log E & =11.8+1.5 M_{S}, \\
\log M_{0} & =1.5 M_{S}+16.1 .
\end{aligned}
$$

But reducing "physics of the earthquake" only to the creation of fault rupture and consequent seismic wave radiation is to oversimplify the problem. It has been repeatedly observed that part of the accumulated preseismic elastic energy is also converted to other kind of energies (electromagnetic and acoustic ones, heat, etc.) and these (yet unknown) conversion mechanisms are probably similar as that to seismic energy. The understanding of such preseismic processes is fundamental to plan and design earthquake prediction techniques on a deterministic basis, that is, based on the so-called seismo-associated phenomena or earthquake precursors. The latter are phenomena of different types (seismic and nonseismic ones) accompanying the characteristic deformation of rocks during earthquake preparation time or preseismic period, and associated with changes in physical conditions in the so-called preparation focal zone (volume) as defined by standard dilatancy-diffusion and crack-avalanche "dilatancy" models [21-23].

Until now, no exhaustive physical models have been proposed and accepted by the scientific community to be used for a deterministic earthquake prediction approach. What is known on the topic is that in the time interval preceding a seismic fracture, stress and strain energy are accumulated in a fault asperity. Most of investigators consider reasonable to assume this increasing and concentrating stress at depth as a cause of the anelastic volumetric increase (dilatancy) of a relatively small portion of rock, and consequent rock dislocation and microfracturing. This volume of cracked rock at depth (preparation focal zone) is considered as a primary local source of precursor signals. These signals propagating in the surrounding medium allow the earthquake precursors to be observed in a finite region of the Earth's surface (precursor area). Then, in principle earthquake precursors can be used to indicate the impending occurrence of a seismic event. Characteristic sizes of the preparation focal zone and of the precursor area have been estimated by Dobrovolsky et al. [24, 25]. They found the volume $(V)$ of soft inclusion (cracked rock) at depth in the lithosphere versus magnitude $(M)$, is described as follows:

$$
V_{\max }=10^{(1.24 M-4.47)} \mathrm{km}^{3},
$$

which for a spherical volume of radius $(r)$ gives:

$$
r=10^{0.414 M-1.696} \mathrm{~km} \text {. }
$$

The dimension of the precursor region at the earth surface is defined [24] by the radius $(R)$ of the Earth's surface area where preseismic strain changes exceed tidal strains $\left(\approx 10^{-8}\right)$, as follows

$$
R=10^{0.43 M} \mathrm{~km} \text {. }
$$

Relationships between preseismic strain $\mathcal{\varepsilon}$, magnitude $M$, and distance $R$ are

$$
\begin{array}{ll}
\varepsilon=\frac{10^{1.5 M-9.18}}{R^{3}} & \text { for } M<5.0, \\
\varepsilon=\frac{10^{1.3 M-8.19}}{R^{3}} & \text { for } M \geq 5.0 .
\end{array}
$$

For comparison, we report in Table 1 the characteristic dimensions of the preparation focal zone at depth (i.e., the 
source of earthquake precursors) with those of the precursor region at the Earth's surface. Data are obtained for $4.0 \leq$ $M \leq 7.0$ events, in the simple case of a preparation focal area modelled by a spherical volume $(V)$ and in presence of a homogeneous medium.

It can be seen that by basing on the model by Dobrovolsky et al. [24] characteristic sizes of preparation focal area at depth are relatively small (from a few hundred meters to a few ten of kilometres) when compared with those of the precursor region at the Earth's surface (from a few tens of kilometres to about one thousand of kilometres).

We stress that this result is only valid for local deformation (tilt and strain) and for a homogeneous Earth's crust containing a soft inclusion simulating the rheological behaviour of a preseismic dilatants volume of cracked rock. When a more realistic and complicated geometry and structure is assumed for the Earth's crust in a seismic region and/or when other kinds of earthquake precursors than mechanical ones are considered (for instance electric and magnetic fields), a new general and more specific physical model must be proposed to determine the above-mentioned $r$ and $R$ sizes of the preparation focal zone and precursor area. In particular, the presence of discrete geodynamic structures (crustal blocks) in seismic regions (see, $[16,26]$ ) implies that a preseismic deformation (tilt and strain) field may propagate at different distances and velocities in the different directions from the preparation focal area. This anisotropic space and time distribution of the preseismic deformation field mainly depends on dimensions, geometry, structure, and rheology of crustal blocks and their transition zones $[7,17]$.

Finally, empirical semilogarithmic relationships have also been proposed by several authors between magnitude $\mathrm{M}$ of an impending earthquake and precursory time $\Delta \mathrm{T}$ (interval between the onset time of a precursor signal and the time origin of the earthquake). One of such relationships proposed by Rikitake [27] is

$$
\log \Delta T=0.76 M-1.83 \text {. }
$$

Concerning nonmechanical earthquake precursors, a model of preseismic electromagnetic emissions is in preparation, which first results have been reported in international meetings $[7,12,28]$.

\section{More Reliable Ground and Space Earthquake Precursors}

In general, earthquake precursors can be divided in the two classes of so-called seismic and nonseismic phenomena. In the class of seismic phenomena are included seismic gap, decreasing (seismic quiescence) and increasing background seismicity, and change in the seismic wave velocity. The list of nonseismic phenomena includes numerous earthquake precursors of very different types as phenomena directly reconciled with local deformations (ground elevations and tilts, strains in rock, water levels in wells, etc.) or of other kind as electric and magnetic fields, EM emissions,
TABLE 1: Sizes of earthquake preparation zone $(r)$ and precursor region $(R)$ for $4.0 \leq M \leq 7.0$.

\begin{tabular}{lcc}
\hline$M$ & $r(\mathrm{~km})$ & $R(\mathrm{~km})$ \\
\hline 4.0 & 0.1 & 52 \\
5.0 & 2.5 & 141 \\
6.0 & 6.0 & 380 \\
7.0 & 41.3 & 1023 \\
\hline
\end{tabular}

electric resistivity in rock, acoustic emissions, gas exhalations (mainly radon and helium), and so forth. The time scale of an earthquake prediction attempt is by convention generally classified as short term ( $\approx$ hour-days), long-term ( $\approx$ yearsdecades), intermediate-term ( $\approx$ weeks-years), according to the expected time interval to the earthquake (precursor time). Really, only short-term and intermediate term time scales can be considered for a true deterministic earthquake prediction methods, since long-term one, in practice, can be identified with the seismic assessment of the seismic hazard of a given zone and, then, associated with the statistical probability for the occurrence of large earthquakes.

3.1. A Possible First Empirical Approach to Deterministic Earthquake Prediction Based on Precursory Phenomena. A deterministic earthquake prediction method based on precursory phenomena has not yet been proposed. At this purpose, the combination of simultaneous and continuous observations of mechanical medium-term precursors and electromagnetic short-term ones in selected seismic test areas could be of particular importance in determining, within the time interval of the short-term precursory time (hour-days), the epicentre, the magnitude and time of occurrence of an impending earthquake.

In principle, as a first empirical approach, a possible method could be to combine the most reliable medium-term and short-term earthquake precursors, as follows.

(a) First Warning/Alert. One could imagine using the onset times of the anomalous medium-term (weeks-months) tilt and strain signals recorded by the multi-instrument network working in the seismic test area as a first-time warning.

(b) Second (Final) Warning/Alert. A second (final) time warning could be associated with the onset times of the first anomalous short-term (hour-days) electromagnetic signals pointed out by the same instrumental network. Then, the uncertainty in the estimate of time origin of the event will be ranging from $\sim 1$ hour to days.

(c) Epicenter/Hypocenter. An estimate of the future epicenter could be attempted by the time shifts between the onset times of the different medium-term anomalous mechanical signals observed by the instrumental network and on the basis of the velocity of propagation of the preseismic deformation front through the crust block structures of the observed test area. This velocity is calculated to be of the order of $1 \mathrm{~cm} / \mathrm{s}[16,29-$ $31]$. But this value must be determined for each test area. 


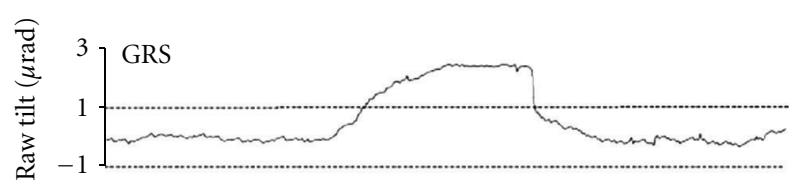

(a)

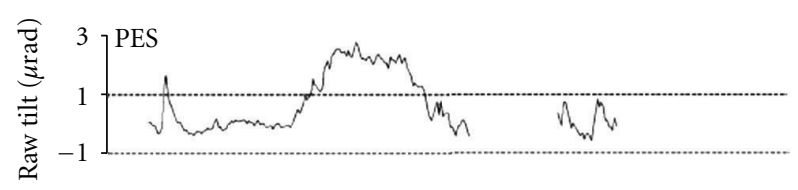

(c)

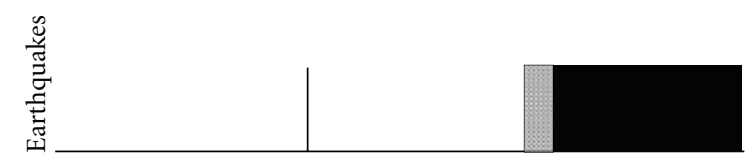

(e)

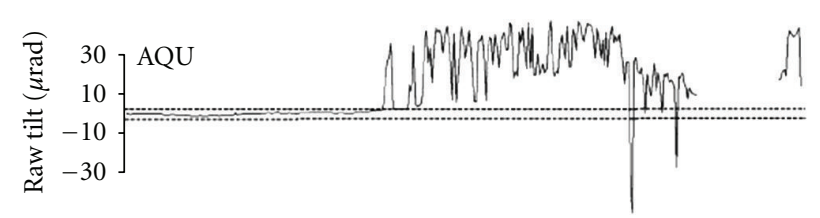

(b)

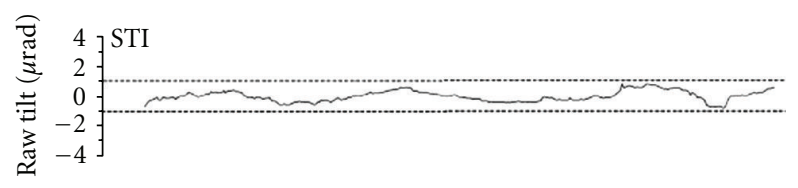

(d)

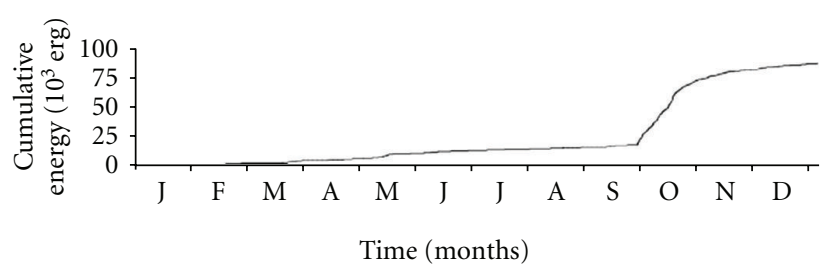

(f)

FIGURE 1: Original figure from the paper by Sgrigna and Malvezzi [16]. Fault creep events recorded during the year 1997 at the GRS (plot (a)), AQU (plot (b)), PES (plot (c)), STI (plot (d)) tilt sites, before the Sept 26, 1997 Umbria-Marches earthquakes $(M=5.7 ; 6.0)$. Plot (e) shows selected earthquakes (e equal/greater than 10-8). A vertical bar marks a single event M4.4 occurred on May 12; two adjacent shadow and black rectangles of arbitrary amplitude represent two time intervals characterized by the occurrence of a preseismic swarm (lasting a few weeks with a peak event M4.4 on September 3), and of several thousands of aftershocks recorded in the following months, respectively. The two main shocks M5.7; 6.0 of September 26 occurred in the time interval between those marked by shadow and black areas. Plot (f) is the cumulative energy released by earthquakes in 1997.

(d) Magnitude. Finally, the magnitude could be roughly estimated on the basis of the empirical relationships between magnitude and precursory time (e.g., (6) in Section 2) by the time shifts between the onset times of all the couple of medium-term and short-term signals observed at each site of the instrumental network. The use of amplitudes of such signals to calculate the magnitude appear to be more questionable since some spatial differential amplification effects (site effects) are observed in the different sites (then, in the different blocks) where instruments are located. An example of such site effect can be observed in Figure 1.

But before applying, any deterministic method of prediction quantitative specific physical models, unavailable at moment, must be proposed for each test area in order to describe the geodynamics and rheology of crustal blocks and relative transition zones, as well as the physical mechanisms underlying the mechanical and electromagnetic preseismic sources. In particular, to justify the observations is necessary to model the shape, onset times, and durations of precursory signals, thus, reconciling them with the preseismic source behaviour and characteristics (space localization, dimensions, geometry, space orientation, rock yielding conditions, and catastrophic rupture mechanisms).

Only at this stage, an exhaustive and general physical interpretation of such precursors could be of help in reducing the uncertainty (physical error) in the estimation of the epicentral position, magnitude, and time of origin of an impending earthquake, then in contributing to define an acceptable deterministic earthquake prediction.
Up to now, there have been systematic observations of mechanical intermediate-term and electromagnetic shortterm precursors, which have been shown to be more suitable for the above-mentioned future applications. To give an idea (though not exhaustive) of the state-of-the-art in the topic, the main results are presented here for ground and space observations and divided into intermediate-term and short-term precursors, respectively. A significant ground intermediate-term mechanical precursor is shown in Section 3.2 and a summary, even not exhaustive, of the principal characteristics of ground and space short-term SEME precursors is reported in sub-Section 3.3 (Tables 2 and 3).

3.2. Ground Creep-Related Intermediate-Term Precursors. A number of interesting results concerning anomalous surface tilt variations observed in local seismic regions during earthquake preparation have been reported over the years. They include the observation and modeling of creep-related tilt perturbations $[16,31,32]$, precursory tilts detected before local and teleseismic earthquakes [29,33], coseismic and postseismic tilts $[34,35]$. These anomalies are easily detectable by tiltmeters $[16,31,36-38]$ and considered by many authors $[17,29,31,33,39-43]$ to be intermediate-term earthquake precursors. The transmission of substantial stress over large distances has been debated $[7,16,44]$.

Continuous hourly ground tilt data collected by the TELLUS tiltmeter network from 1981 to the present in the seismic region of the Central Apennines of Italy 
TABLE 2: A summary of ground-based short-term (hour-days) SEME precursors.

\begin{tabular}{|c|c|}
\hline Observations & Modeling \\
\hline $\begin{array}{l}\text { EKE changes. } \\
\text { B field changes. } \\
\text { Ground potentials [59-61]. }\end{array}$ & $\begin{array}{l}\text { Streaming Potentials by saline } \\
\text { water moving through porous } \\
\text { rocks }[62,63] \text {. } \\
\text { Stress applied effects to rocks } \\
\text { containing piezoelectric } \\
\text { materials [64-67]. }\end{array}$ \\
\hline $\begin{array}{l}\text { ULF-ELF SEME }[68-71] . \\
\text { ULF-HF SEME }[26,72-77] \text {. } \\
\text { VLF E field changes }[78,79] .\end{array}$ & $\begin{array}{l}\text { EM behaviour of rocks } \\
{[55,80-83] .} \\
\text { Rocks become a source of highly } \\
\text { mobile electric carriers that } \\
\text { increase electric conductivity and } \\
\text { propagate through the rock as a } \\
\text { charge cloud [84]. }\end{array}$ \\
\hline $\begin{array}{l}\text { E field changes and gas } \\
\text { emissions by rock } \\
\text { microfracturing }[31,85,86] \text {. }\end{array}$ & $\begin{array}{l}\text { Number and dimensions of } \\
\text { microcracks and redistribution } \\
\text { of pore fluids. } \\
\text { Motion of saline pore fluids and } \\
\text { formation of intergranular water } \\
\text { film }[55,86] \text {. }\end{array}$ \\
\hline $\begin{array}{l}\text { Low-frequency SEME } \\
\text { Laboratory investigations } \\
\text { about conversion of } \\
\text { accumulated preseismic elastic } \\
\text { energy to EM energy [87]. }\end{array}$ & $\begin{array}{l}\text { Rock as "igneous rock battery" } \\
\text { due to the activation of positive } \\
\text { hole charge carriers by stress. } \\
\text { Dislocation movement leading to } \\
\text { bond breaking of Si-OO-Si } \\
\text { peroxy links [87]. }\end{array}$ \\
\hline $\begin{array}{l}\text { Mechanical and EM signals } \\
\text { from laboratory to geophysical } \\
\text { scale }[88] \text {. }\end{array}$ & $\begin{array}{l}\text { First attempts to justify effects of } \\
\text { applied stress on rocks [88]. }\end{array}$ \\
\hline
\end{tabular}

has systematically provided evidence of intermediate-termearthquake tilt precursors [16]. An example of creep-related intermediate-term tilt precursors detected by the TELLUS network has been pointed out by Sgrigna and Malvezzi [16] on the occasion of the Umbria-Marches seismic sequence with two main shocks ( $M=5.7$ and 6.0) with epicentres very close one each other (about $3 \mathrm{~km}$ ) occurred on September 26,1997 , at 00:33 and 9:40 UTC, respectively. Figure 1 is the original figure taken from the paper by Sgrigna and Malvezzi [16] to which we invite to refer for the description of geodynamics of local crustal block system, characteristics of seismicity, and selection criteria for earthquakes and residual tilt signals.

The main features of the intermediate-term preseismic tilts reported in Figure 1 may be summarized as follows (Figure 1)

(1) Raw tilt data, filtered by meteorological and secular tectonic effects, revealed intermediate-term preseismic tilts with a shape, amplitude, and time duration similar to those already obtained in the same area $[16,31,42,43]$.

(2) Tilts are shifted in time relative to each other, indicating a possible propagation of the preseismic strain field from the preparation focal area to the tilt sites, through the rigid blocks of the region $[26,45]$
TABLE 3: A summary of space-based short-term (hour-days) SEME precursors. Symbol $\Rightarrow$ means then.

\begin{tabular}{ll}
\hline Observations & Modeling \\
\hline & SEME-waves generation $\Rightarrow$ \\
& Lithospheric lowpass filter on \\
Ionospheric E, B fields changes & ULF-HF-waves $\Rightarrow$ ULF-ELF \\
& SEME-waves may reach the Earth \\
& surface and enter into near-Earth \\
& space $[86,98,99,102-109]$.
\end{tabular}

Ionospheric plasma temperature ULF-ELF

and density changes TEC. SEME-waves-Ionospheric

Decrease at the ionospheric F2 plasma interaction mechanisms peak $f 0$ F2 [110-112]. $\quad[71,103,113,114]$.

Alfven-wave radiation (from DC to some hundred $\mathrm{Hz}$ ) propagates along the geomagnetic field lines $\Rightarrow$ Resonant wave-particle

SEME-waves. Van Allen radiation belt particle interaction at the radiation belt precipitation. PBs (Particle Bursts)

$[8,18,48-50,53,115-118]$. and protons from a few $\mathrm{MeV}$ to several tens of $\mathrm{MeV} \Rightarrow$ Particle precipitation as a result of pitch angle diffusion

$[7,8,50,51,92,119]$.

Fair weather currents [98].

Variations in the atmospheric Modification of spectral content conductivity profiles [98, 99]. of ELF-VLF radio noise during lightning discharges [99].

ULF emissions of $0.2 \mathrm{nT}$ penetrate through the ionosphere $\Rightarrow$ cyclotron interaction with protons of

ULF SEME-waves and VLF SEME-waves from Satellite Intercosmos-24 [89]. $0.5-5 \mathrm{MeV}$ near the magnetic equatorial plane $\Rightarrow$ Proton distribution function becomes unstable for the Cherenkov VLF radiation of $0.1-20 \mathrm{kHz}$ [119].

Amplitude and phase variations of radio-signal propagating in the earth-ionosphere wave guide).

Disturbances in Omega and

Abnormal ionisation in the lower ionosphere [121].

Loran VLF radio-waves propagation [120-122].

Short-term electric field strength attenuation of the Radio Monte Tropospheric radio defocusing Carlo (RMC) LF radio-signal mechanisms [26].

[26].

Atmospheric anomalies caused Significant enhancement of VHF by VHF SEME-waves [123]. EM-waves beyond line-of-sight [123].

separated by inclined transition zones, filled by fault viscoelastic material $[16,29,39,46]$.

(3) A characteristic so-called site effect is evident in the signal amplification observed at the AQU tilt site when comparing amplitudes of this signal with those recorded at GRS and PES. 
(4) Experimental values for the velocity of propagation are in agreement with previous results.

(5) The intermediate-term preseismic tilts have been interpreted as viscoelastic creep strains in the fault material, due to the propagation of stress-strain fields from the dilatant focal area to the observation sites.

(6) One-dimensional and two-dimensional numerical models have been proposed to justify qualitatively the main features (tilt anomaly shape and onset time delay and decay of anomaly amplitude with distance from the earthquake preparation zone) of the preseismic ground tilt behaviour [17, 26, 30]. Horizontal movements of rigid crustal blocks were also considered by Gabrielov et al. [47].

3.3. Ground and Space Short-Term Seismo-Associated EME Signals. Studies of seismoelectromagnetic emissions (SEME) have been developed for a few decades both at the Earth's surface and in the near-Earth space (atmosphere, ionosphere, and magnetosphere).

In recent years, interest has been increasing in the SEME signals consisting of a broad band (from approximately DC to a few tens of $\mathrm{MHz}$ ) EM fields generated and transmitted by seismic sources into the near Earth's space before, during and after an earthquake. SEME characteristics and detectability as well as the effects they provoke in space (ionospheric and magnetospheric perturbations), have a very interesting and promising nature as a short-term earthquake predictor.

Several significant ground and space observations and modelling of such precursors are summarized in Tables 2 and 3 , respectively.

Note that in the case of very shallow and strong earthquakes, when the size of the preparation focal zone is greater than the hypo-central depth (see relations (4) and (5)), also the higher frequency content of DC-HF SEME radiation could be transmitted from the Earth's surface to the near space.

Concerning radiation belt particle precipitation most preseismic $\mathrm{PBs}$ have been collected by satellites near the South Atlantic Anomaly (SAA) at altitudes generally between about 400 and $1200 \mathrm{~km}$ [48-50]. Moreover, the lower limit of the portion of the ionosphere-magnetosphere transition zone (i.e., the altitude where preseismic EME-waves may be captured in the geomagnetic field lines and, then, propagate up to the inner radiation belt) has been estimated from PBs space observations and resulted to be around $300-500 \mathrm{~km}$ $[8,51]$. Besides, the lifetime of the longitudinal drift of $\mathrm{PBs}$ is determined by the particle loss rate during particle interaction with the residual atmosphere of the Earth. A lifetime of the order of several tens of minutes is obtained for electrons and protons of several tens of $\mathrm{MeV}$ [52]. During this time, particles may drift longitudinally around the Earth along the L-shell corresponding to the EME ground source location $[50,53]$.

This is a crucial factor for a possible use of preseismic PBs as an earthquake predictor since the longitudinal drift makes the $\mathrm{PB}$ detection possible by particle detectors installed on board satellites.

Another important factor is the opposite drift direction of positive- and negative-charged particles, which in principle could allow the location of EME wave-particle interaction zone (i.e., the PBs space source location) to be identified.

Nevertheless, there is still an open debate on the mechanism to be invoked in order to justify the phenomenology under study and, in particular, whether the very low amplitude ULF/ELF EM waves may reach the inner Van Allen radiation belt and cause the above-mentioned coupling phenomena. In fact, the electric and magnetic components of these EME-waves are estimated to be of only some fraction of $\mathrm{mV} / \mathrm{m}(\mathrm{Hz}) 1 / 2$ and of some fraction of $\mathrm{nT} /(\mathrm{Hz}) 1 / 2$ or less, respectively [54]. A qualitative representation of the space phenomenology is presented in Figure 2.

\section{The AUSONIA “Space Scientific Platform"}

After a first satellite project named ESPERIA (Earthquake investigations by Satellite and Physics of the Environment Related to the Ionosphere and Atmosphere) was planned and designed for the Italian Space Agency (ASI) with objectives to only detect seismic precursors, a second more complete satellite project named AUSONIA was proposed with aim at also studying other phenomena of the near-Earth space accompanying those associated with seismic events and which may interact with precursor signals. For a correct approach to an earthquake precursors study, all these signals must be recognized, isolated, and filtered from the data. A detailed technical description of the ESPERIA space mission concept can be found in the ASI Phase A Report [12] and in Sgrigna et al. 2008.

AUSONIA (Advanced mUlti-Instrument Satellite for a combined Observation of magNetosphere, Ionosphere, Atmosphere, and associated phenomena) is an Italian space project proposal submitted to the Italian Space Agency (ASI) within an ASI AO for earth observation [14]. AUSONIA was planned and designed by an Italian Consortium led by the Roma Tre University of Rome (Vittorio Sgrigna, Principal Investigator).

The aim of the AUSONIA project is to design and construct a small space platform planned with an multiinstrument payload and a LEO mini-satellite mainly concerned with the monitoring and mapping of the ionosphere-magnetosphere transition region. The scientific program is based on coordinated, continuous, and simultaneous space and ground-based observations, and on mutual data comparison with other missions of similar quality.

AUSONIA was proposed after the IUGG resolution in support of ESPERIA (2007 IUGG resolution N.5) (http:// www.iugg.org/resolutions/), which welcomes the planning of several nations to launch ionospheric monitoring satellite missions. As mentioned above AUSONIA includes both the study of perturbative phenomena in the topside ionosphere (already planned for ESPERIA) and the field mapping of the same region to give a contribution in defining the IGRF and IRI models. 
A qualitative representation of the phenomenology

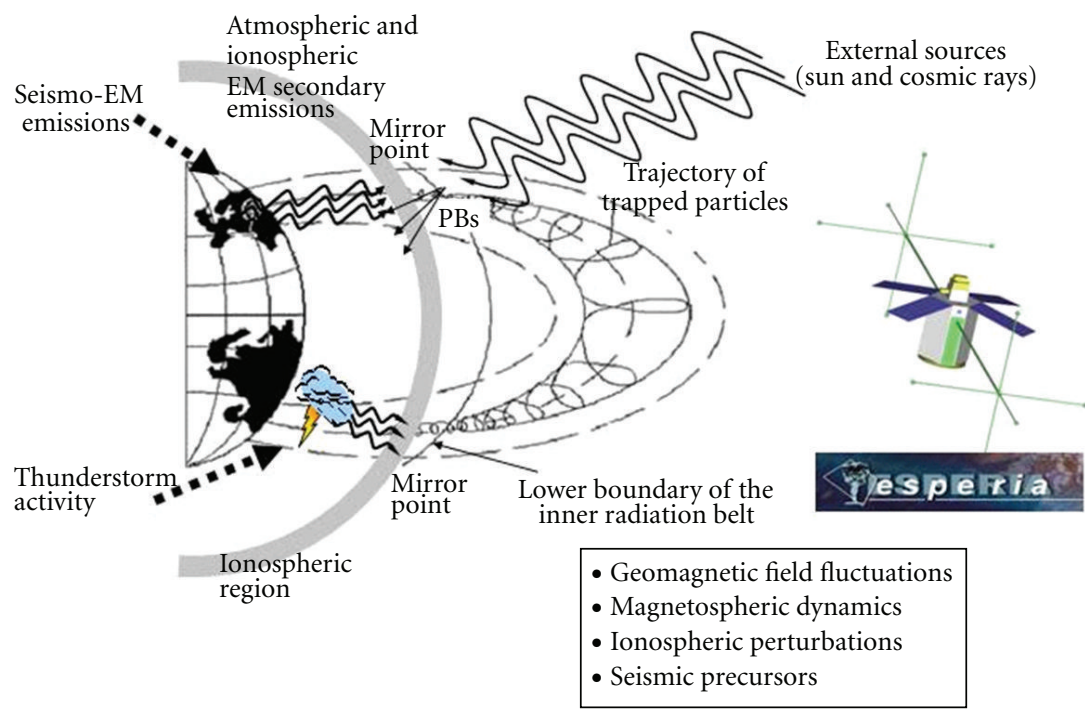

FIGURE 2: A schematic representation of the solid earth and near-Earth space (atmosphere, ionosphere, magnetosphere) with main associated physical phenomena: seismo-EM emissions, their propagation and interaction with ionospheric plasma and magnetospheric trapped particles, cosmic rays and solar effects into the magnetosphere, and tropospheric TLE and TGF emissions. Trajectories of charged particles trapped by the geomagnetic field lines are represented in a meridian plane.

4.1. AUSONIA Scientific Aims. Scientific and methodological aspects of the AUSONIA space project are reported in Table 4.

\subsection{Experiments Planned on Board the AUSONIA Satellite.} On the AUSONIA satellite are planned five experiments, MAGIA, ELECTRA, LUCE, CIELO, and TERRA. They are devoted to monitor geomagnetic field, plasma, and particle environment in the ionosphere-magnetosphere transition zone as well as to study optical/UV and X/gamma emissions induced by tropospheric activity. The MAGIA (MAGnetic Instrument Array) experiment is constituted by a scalar, a fluxgate, and a 3-axes search-coil magnetometers to detect stationary, lower-frequency and higher-frequency magnetic field. The magnetometers are installed on the tips of two deployable booms (Boom_M_Right and Left, each one 5 meters long from the satellite spacecraft) to reduce the electromagnetic interference from the satellite equipments. The ELECTRA (ELECTRic field Analyser) experiment consists of 4 electric preamplified probes, each one installed on the tips of 4 meters deployable booms ( 4 meters long, called ELECTRA_Zenith, TAN, Right, Left) to allow to measure the 3 electric field components in the frequency range from about DC up to about $10 \mathrm{MHz}$ ). The MAGIA and ELECTRA sensors can highlight the correlation with lightnings and reconstruct the dynamics of the electromagnetic atmosphere-ionosphere. These measurements are also essential to study the LEP (lightning-induced electron precipitation) and all the phenomena of disturbance of the Van Allen belt-induced storms, in the AUSONIA project are included optical and UV detectors devoted to the observation of TLEs with high spatial and temporal resolution in specific frequency bands. Measurements are taken with video cameras and photometers with the hope of reconciling the need for high capture rate with the high-resolution image. The optical-UV for these observations are concentrated in the experiment LUCE in two separate blocks oriented to nadir and to limb, respectively. Each block consists of 2 cameras with filters optimized for the shooting of red sprites (VID1) and lightning (VID2), respectively, and 4 photometers ( $\mathrm{PH} 1,2,3,4)$ for UV-visible measurements. The main characteristics of the LUCE experiment are summarized in Table 5. The precipitation of particles of the Van Allen belts was observed by several satellite missions, but many questions need an answer about the temporal and spatial stability of the Van Allen belts and the dynamics of interaction disturbances associated with magnetic storms, the electromagnetic emissions of tropospheric origin, the EM emissions of anthropogenic origin, and so forth. Other themes of topical scientific interest are the $\mathrm{X}$ and gamma emissions from the troposphere (TGF). They represent a background for satellite missions such as AGILE designed to explore gamma bursts from the sky. To study of these phenomena, the TERRA detector is designed to be installed on board the AUSONIA satellite. The experiment consists of two identical modules: TERRA_Nadir and TERRA_Tan oriented to Nadir and in the opposite the speed of the satellite, respectively. X- and gamma-ray detectors will be constantly active during the optical and EM measurements to allow to investigate the characteristics and origin of the TGF and their correlation with TLE. TERRA aims at revealing X- and gamma-ray bursts (TGF) from the Earth's troposphere. This to map TGF phenomena, to measure the $\mathrm{X}$-ray spectrum observed range and determine the mechanisms that generate them, to observe the precipitation of 
TABLE 4: Science and methods of the Ausonia project.

\begin{tabular}{|c|c|c|c|}
\hline & Scientific objective & Expected results & International collaborations \\
\hline $\begin{array}{l}\text { Geomagnetic field } \\
\text { mapping }\end{array}$ & $\begin{array}{l}\text { Main field and secular variation } \\
\text { will be the principal goals. }\end{array}$ & $\begin{array}{l}\text { Contribution to the IGRF. A better } \\
\text { knowledge of the Earth's core } \\
\text { dynamics, secular variation, field } \\
\text { inversions and crustal anomalies. } \\
\text { 3D reconstruction of the mantle } \\
\text { conductivity. }\end{array}$ & $\begin{array}{l}\text { Synergy with SWARM mission, } \\
\text { INGV ground network and } \\
\text { SEGMA-ULF geomagnetic } \\
\text { networks. }\end{array}$ \\
\hline $\begin{array}{l}\text { Monitoring of } \\
\text { ionosphere and } \\
\text { plasmasphere }\end{array}$ & $\begin{array}{l}\text { Simultaneous measurements of } \\
\text { local changes in the topside } \\
\text { ionosphere and space and time } \\
\text { variability of plasmasphere. }\end{array}$ & $\begin{array}{l}\text { Contributions to the IRI model, } \\
\text { ionospheric tomography, study of } \\
\text { space weather events by in situ } \\
\text { measurements and plasmaspheric } \\
\text { TEC investigations. }\end{array}$ & $\begin{array}{l}\text { Collaboration with NASA } \\
\text { missions C/NOFS and STPSAT1. } \\
\text { Use of CITRIS-like detector to } \\
\text { collect signals from CERTO } \\
\text { satellite and DORIS radio } \\
\text { beacons terrestrial network. } \\
\text { Comparisons with INGV and } \\
\text { DIAS ionosonde data. }\end{array}$ \\
\hline
\end{tabular}

\begin{tabular}{|c|c|c|c|}
\hline $\begin{array}{l}\text { Detection of transient } \\
\text { phenomena } \\
\text { associated with } \\
\text { thunderstorms }\end{array}$ & $\begin{array}{l}\text { Detection of tropospheric } \\
\text { transient luminous emissions } \\
\text { (TLE), lightnings, terrestrial } \\
\text { gamma ray flashes (TGF) and } \\
\text { related energy transfer } \\
(\sim 0,25-1 G W) \text { from troposphere } \\
\text { to iono-magnetosphere. }\end{array}$ & $\begin{array}{l}\text { Understanding of TLE e TGF } \\
\text { effects in the framework of the } \\
\text { ionosphere-magnetosphere } \\
\text { couplings. }\end{array}$ & $\begin{array}{l}\text { Complementary observation } \\
\text { campaigns of TLE e TGF } \\
\text { phenomena to be carried out } \\
\text { with the TARANIS satellite. }\end{array}$ \\
\hline $\begin{array}{l}\text { Study of } \\
\text { iono-magnetospheric } \\
\text { perturbations due to } \\
\text { EM emissions of } \\
\text { terrestrial origin }\end{array}$ & $\begin{array}{l}\text { Study of the possible effects } \\
\text { produced in the near-Earth space } \\
\text { by EM emissions of seismic and } \\
\text { volcanic origin. }\end{array}$ & $\begin{array}{l}\text { The AUSONIA team can take } \\
\text { profit from the expertise of the } \\
\text { previous ESPERIA project (see the } \\
2007 \text { IUGG resolution N.5, } \\
\text { http://www.iugg.org/resolutions/). }\end{array}$ & $\begin{array}{l}\text { The AUSONIA team is guest } \\
\text { investigator of the DEMETER } \\
\text { mission to study whistlers and } \\
\text { radiation belt particles. }\end{array}$ \\
\hline $\begin{array}{l}\text { Investigation of Van } \\
\text { Allen particle fluxes } \\
\text { and tropospheric } \mathrm{X} / \gamma \\
\text { rays }\end{array}$ & $\begin{array}{l}\text { Study of temporal stability of the } \\
\text { Van Allen radiation belts, } \\
\text { detection of particle } \\
\text { precipitation and tropospheric } \\
\text { and cosmic } \mathrm{X} / \gamma \text { emissions. }\end{array}$ & & $\begin{array}{l}\text { A few key persons of the AGILE } \\
\text { mission are also members of the } \\
\text { AUSONIA team. }\end{array}$ \\
\hline
\end{tabular}

particles from the Van Allen belts induced magnetic storms, tropospheric phenomena, seismoelectromagnetic emissions and emissions from anthropogenic EM, to measure range, direction, and temporal variation of the flow of precipitating charged particle, to reveal the runaway electrons, to study the interactions between whistler waves and trapped particles, to generate a trigger signal upon detection of a TGF and enable the acquisition of other experiments such as LUCE, to gather information on the length, height, changes in TGF, and to acquire a statistically significant amount of TGF events as a function of local time, geomagnetic conditions, and so forth.

Figure 3 illustrates the general satellite layout.

Planned experiments and instruments and their positioning on board the AURONIA satellite are reported in Table 5 .

4.3. Mission Characteristics. At this overpreliminary step, the final parameters have not yet been completely defined. In Table 6, values are given for a MITA platform solution and a sun-synchronous orbit. The satellite orbit altitude has be chosen to optimise observations at the sunrisesunset local time for a better identification of seismo-induced ionospheric disturbances. In fact, as reported by Molchanov and Hayakawa $[55,56]$ and Chuo et al. [57], an increase in the sporadic E-layer critical frequency at the terminator time (sunrise and sunset) is observed within 5 days before the earthquake that determines a corresponding increase in the D-layer electron density and a variation of the VLF propagation at the terminator time. Should AUSONIA be installed on board of another spacecraft, budgets, volume, orbit inclination, and altitude can be changed accordingly.

4.4. Comparisons between AUSONIA and Other Missions. In Table 7, the AUSONIA payload is compared with that of others missions of similar quality. It appears evident the AUSONIA capability in carrying out multiparametric measurements, as well as its character of "small scientific platform" for earth observation.

\section{The EGLE and ARINA Space Experiments}

A few ESPERIA instruments (such as the particle detectors LAZIO and ARINA, and the search-coil magnetometer EGLE) have been built and tested in space $[15,19,58]$. EGLE was a technological demonstrator installed on board the International Space Station (ISS) on April 15, 2005, within the LAZIO-EGLE experiment of the ENEIDE mission, which has been coordinated by the European Space Agency (ESA) 


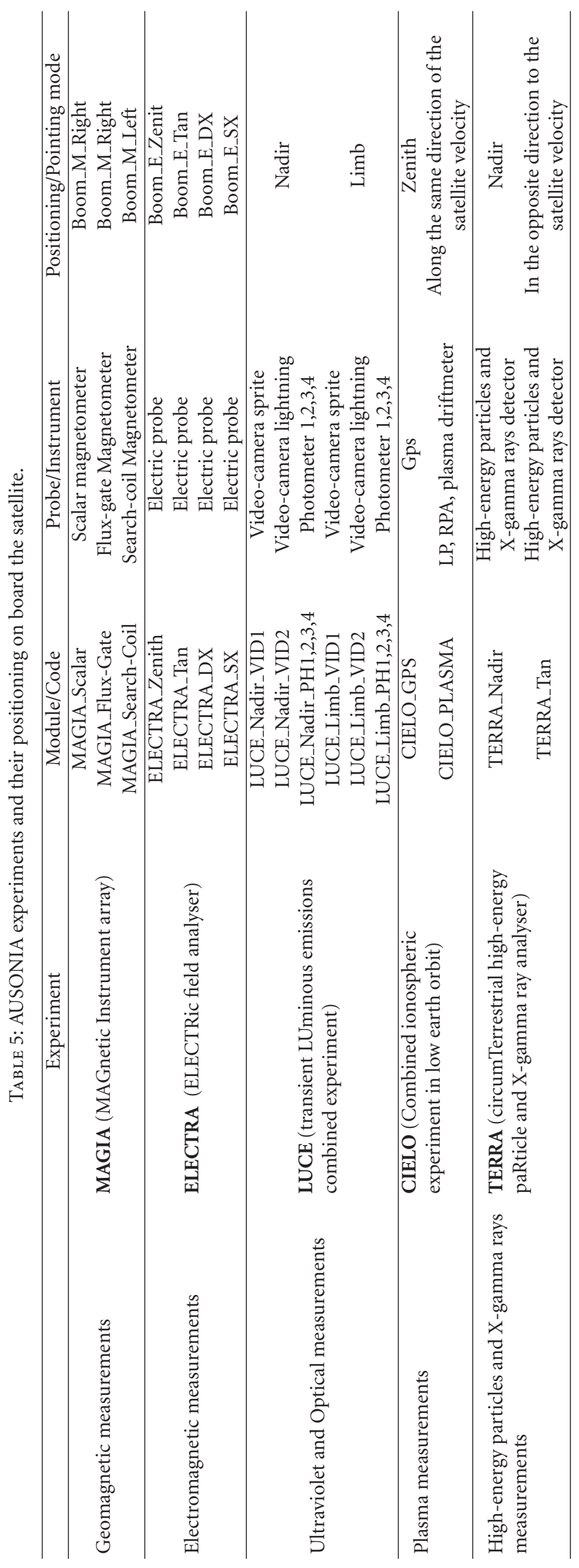


TABLE 6: AUSONIA satellite mission characteristics.

\begin{tabular}{ll}
\hline \multirow{3}{*}{ Orbit } & Sun-synchronous circular orbit $98^{\circ}$ inclination \\
& $\begin{array}{l}\text { Altitude between } 600 \text { to } 800 \mathrm{~km} \text { (TBD). See also notes after Table } 3 \text { in Section } 3.3 \\
\text { Revisit time: } \leq 24 \mathrm{~h}\end{array}$ \\
\hline \multirow{3}{*}{ Budgets } & Power satellite total: $\sim 270 \mathrm{~W}$ (Payload total: $120 \mathrm{~W}$; platform total: $150 \mathrm{~W})(\mathrm{TBD})$ \\
& P/L data: $\sim 306 \mathrm{kbps}(36,5 \mathrm{Gbit}$ of daily data, margin included) (TBD) \\
& Payload mass: $\sim 120 \mathrm{~kg}(\mathrm{TBD})$ \\
\hline \multirow{2}{*}{$\begin{array}{l}\text { Attitude orbit } \\
\text { control system }\end{array}$} & Attitude determination: $0.001^{\circ}(\mathrm{TBD})$ \\
& Attitude Accuracy $\left(3\right.$ axes): $0.1^{\circ}(\mathrm{TBD})$ \\
& 3 reaction wheels, 3 magnetic coils, 2 star trackers, 3 gyroscopes, GPS receivers, three-axis \\
& magnetometer, 10 sun sensors \\
\hline \multirow{3}{*}{ Spacecraft } & Platform MITA or other platform of similar quality (TBD) \\
& Nadir pointing \\
\hline Mission duration & Thrusters applied to the platform (constant altitude and/or possible orbit changes) (TBC) \\
\hline
\end{tabular}

TABLE 7: AUSONIA instrument payload compared with that of other missions of similar quality.

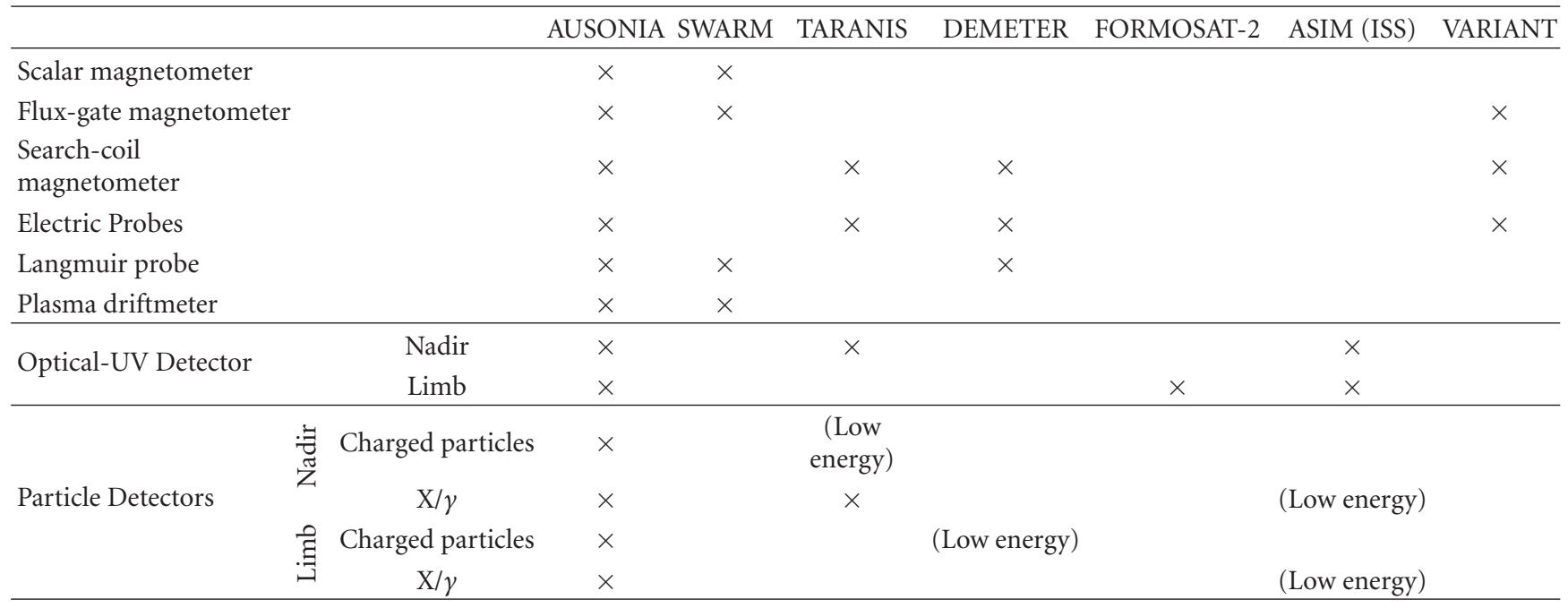

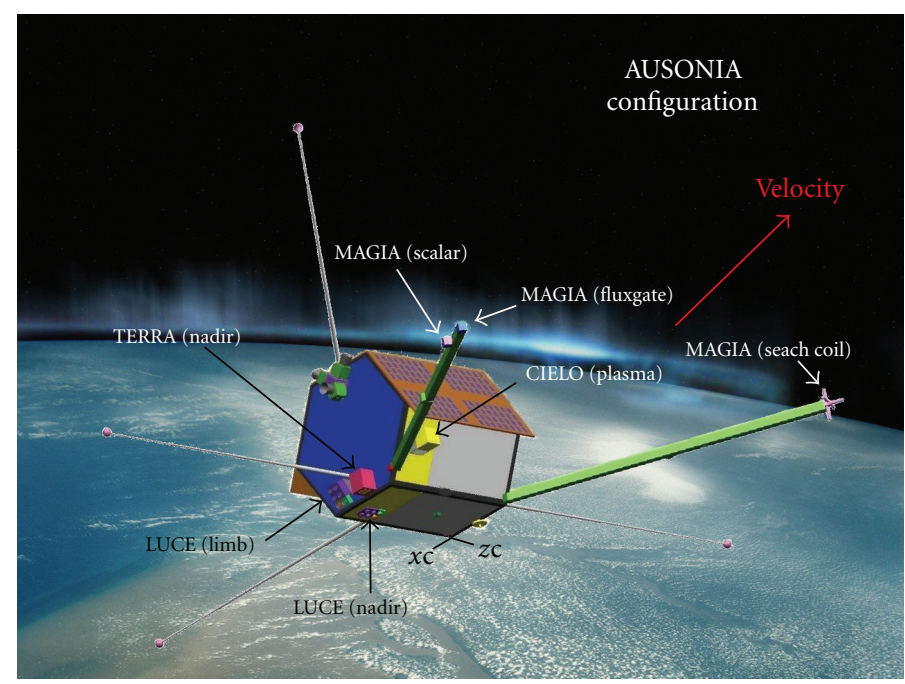

FIGURE 3: Schematic representation of the AUSONIA satellite project. 


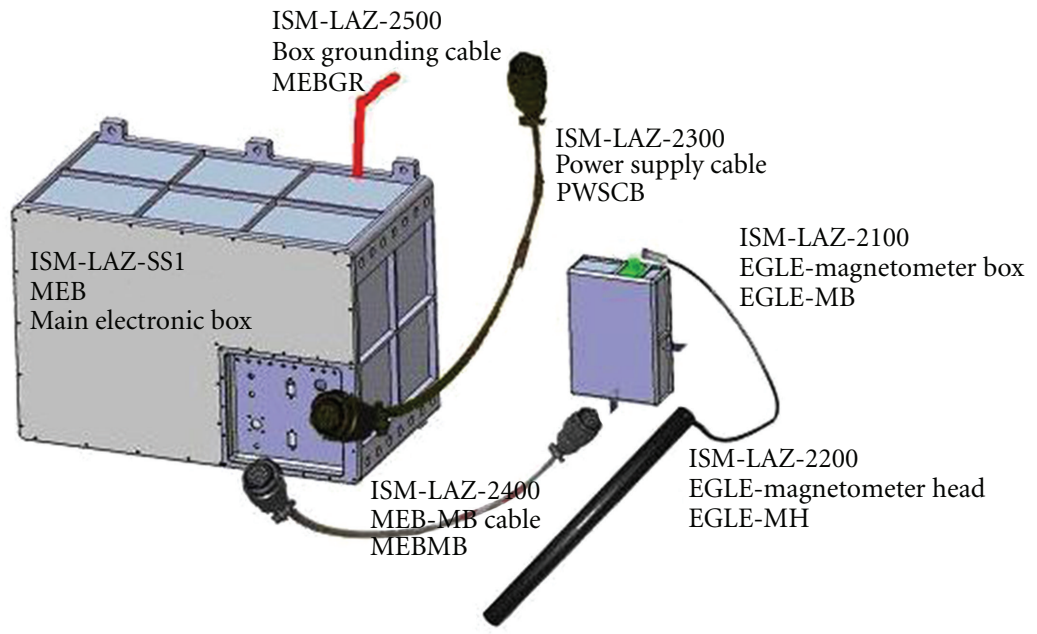

FIGURE 4: EGLE experimental setup.

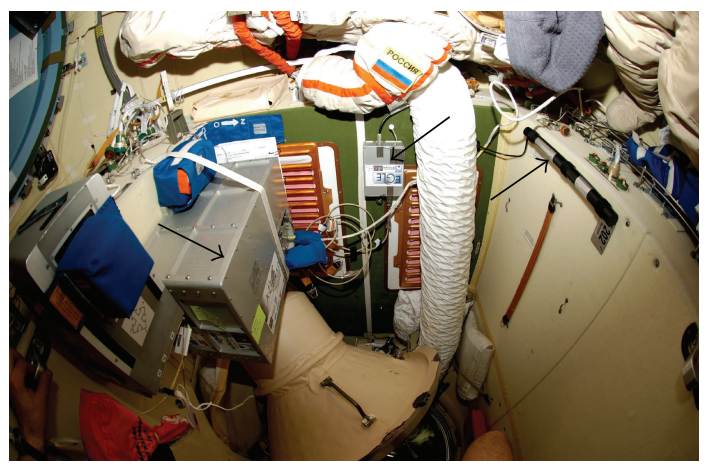

FIGURE 5: EGLE inside the PIRS module of the ISS. Arrows indicate MEB (left), EGLE-MB (front), and EGLE-MH (right).

and received contributions from the Italian National Institute of Nuclear Physics (INFN) and Regione Lazio. The launch of ARINA occurred on June 15, 2006, within the PAMELA mission. ARINA will perform particle measurements on a quasipolar orbit RESURS DK-1 Russian LEO satellite. Data from ARINA, EGLE, and TELLUS may be studied together with those collected by DEMETER, through the Demeter Guest Investigator Programme.

\subsection{The EGLE Magnetic Experiment on Board the Interna-} tional Space Station. The main goal of the EGLE experiment was to test in space an original very broad band search-coil magnetometer and associated data acquisition system based on the 1-Wire technology. The duration of the mission was of 10 days (15 April-25 April 2005).

The characteristics of the EGLE magnetometer are also important within the ISS applications. In fact, the monitoring of the EM environment on board the ISS needs both an appropriate observation methodology and a corresponding experimental equipment design. The continuous monitoring of the EM environment on board the ISS by an advanced magnetic experiment in the ULF-HF band is important in the following areas:

(a) search of space weather conditions in equatorial, middle-latitude, and subauroral ionosphere;

(b) geophysical research of plasma-wave processes connected to solar-magnetosphere-ionosphere-atmosphere-lithosphere interactions;

(c) investigation of the possible relationships between seismic activity and ULF-VLF phenomena possibly related to earthquakes;

(d) continuous monitoring of ULF-ELF-VLF activity in the near-Earth space including ELF-VLF pollution;

(e) Monitoring of natural and man-made variations of the plasma-sphere caused by whistlers.

(f) investigation of EM background and space weather phenomena;

(g) investigation of the effects of the large ISS structure on the propagating wave-front.

The LAZIO-EGLE experiment aims at performing measurements involving:

(1) the radiation environment;

(2) the magnetic environment inside the ISS.

The experiment includes the high-precision lowfrequency magnetometer EGLE (Esperia's Geomagnetometer for a Low-frequency wave Experiment). EGLE is able to measure the intensity and variations in the magnetic field within the ISS and to correlate these measurements with those of particle fluxes. The study of these effects is important to detect electromagnetic field variations and particle pitch angle distribution of the precipitating particles. EGLE experiment is also the first test in space of a data acquisition system based on the 1-Wire technology. 

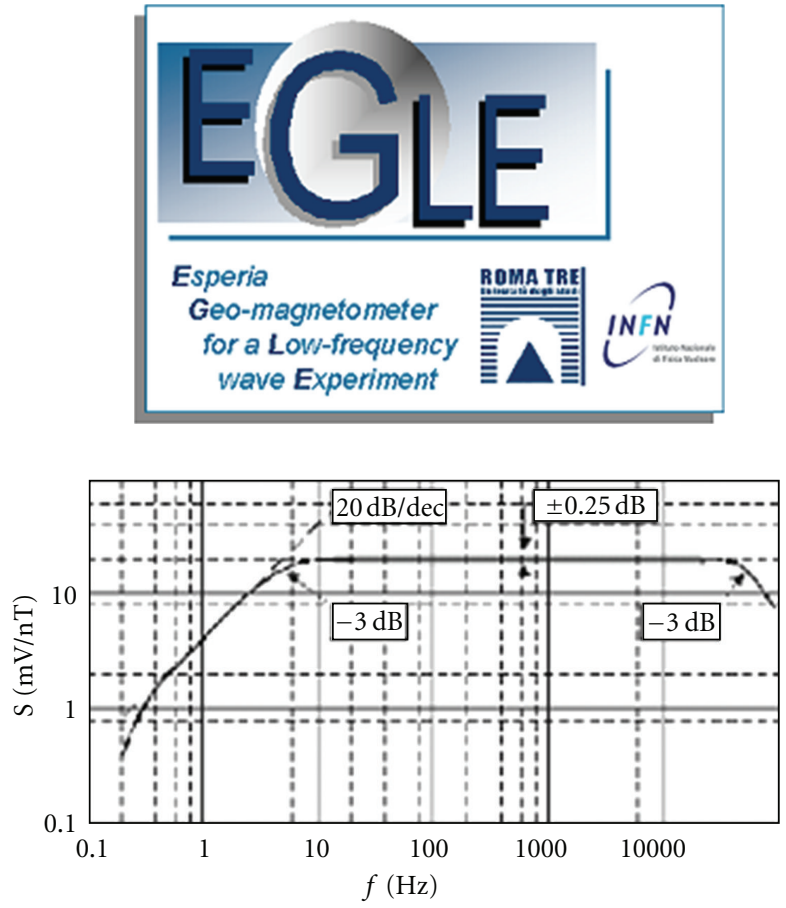

Amplitude-frequency response of the EGLE magnetometer

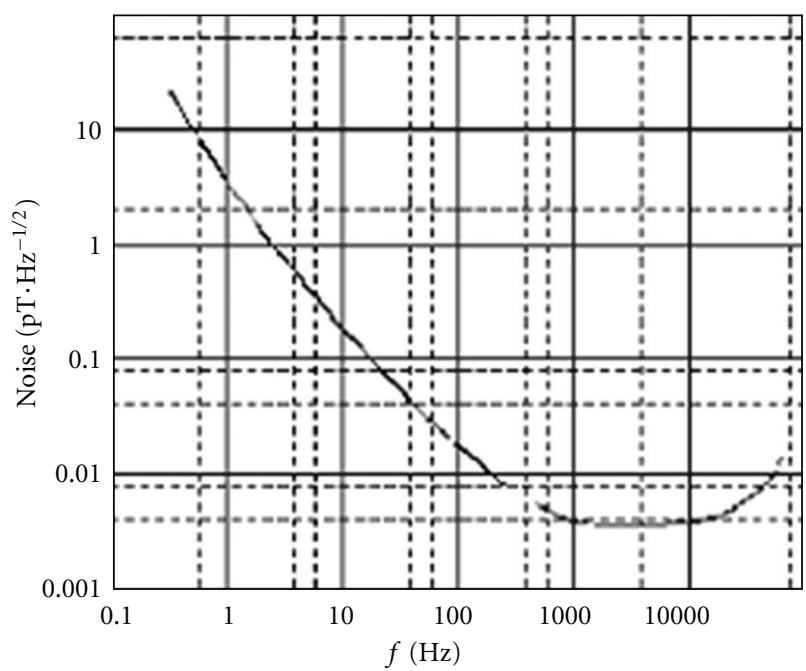

Noise spectral density

\begin{tabular}{|c|c|}
\hline \multicolumn{2}{|c|}{ Basic technical specifications of the EGLE probe MH. } \\
\hline Frequency band of receiver signals & $0.5 \div 50000 \mathrm{~Hz}$ \\
\hline Shape of transfer function & linear-flat \\
\hline Type of output & Symmetrical \\
\hline \multicolumn{2}{|l|}{$\begin{array}{l}\text { Transformation factor at both output } \\
\text { terminals: }\end{array}$} \\
\hline (i) at linear part $(0.5-5 \mathrm{~Hz})$ & $\mathrm{f} * 4 \mathrm{mV} /(\mathrm{nT} * \mathrm{~Hz})$ \\
\hline (ii) at flat part $(5-5000 \mathrm{~Hz})$ & $20 \mathrm{mV} / \mathrm{nT}$ \\
\hline \multicolumn{2}{|l|}{ Transformation factor error: } \\
\hline (i) at flat part of band pass without edges & $\leq \pm 0.25 \mathrm{~dB}$ \\
\hline (ii) at flat part band pass edges & $\leq 3 \mathrm{~dB}$ \\
\hline \multicolumn{2}{|l|}{ Magnetic noise level, $\mathrm{pT} * \mathrm{~Hz}^{-1 / 2}$ : } \\
\hline (i) at $5 \mathrm{~Hz}$ & $\leq 0.4$ \\
\hline (ii) at $100 \mathrm{~Hz}$ & $\leq 0.02$ \\
\hline (iii) at $5 \mathrm{kHz}$ & $\leq 0.004$ \\
\hline (iv) at $50 \mathrm{kHz}$ & $\leq 0.02$ \\
\hline \multirow[t]{2}{*}{ Nominal output load } & $\leq 200 \mathrm{pF}$ \\
\hline & $\geq 50 \mathrm{k} \Omega$ \\
\hline Power supply voltage & $\pm(15 \pm 0.2) \mathrm{V}$ \\
\hline Power consumption & $300 \mathrm{~mW}$ \\
\hline Temperature range of operation & $-30^{\circ} \mathrm{C} \div+50^{\circ} \mathrm{C}$ \\
\hline \multirow{2}{*}{$\begin{array}{l}\text { Outer dimensions (without prominent } \\
\text { parts) }\end{array}$} & $l=400 \mathrm{~mm}$ \\
\hline & $d=32 \mathrm{~mm}$ \\
\hline Length of output cable & $0.7 \mathrm{~m}$ \\
\hline Weight & $\leq 320 \mathrm{~g}$ \\
\hline
\end{tabular}

FIGURE 6: Frequency response and noise spectral density of the EGLE search-coil magnetometer together with technical specifications of the EGLE probe.

The EGLE magnetometer consists of (Figure 4) the following

(i) a single axis search coil probe, the EGLE magnetometer head $(\mathrm{MH})$;

(ii) an electronic interface with amplifiers, filtering, and data acquisition unit (EGLE MB box);

(iii) a 2-m long cable to connect LAZIO MEB and EGLE $\mathrm{MB}$;

(iv) a 1-Wire to RS232 serial adapter on the LAZIO pc tower.
Magnetic field signals detected by the EGLE-MH probe are amplified, filtered, and recorded by the EGLE acquisition and data handling board located in the EGLE-MB box. The EGLE magnetometer magnetic field data are collected in four frequency bands (DC through to $20 \mathrm{~Hz}$ raw data; $0.5-40 \mathrm{~Hz}$; $500 \mathrm{~Hz}-5 \mathrm{kHz} ; 20-40 \mathrm{kHz}$ integrated r.m.s. data).

Gaps between these frequency ranges have been chosen to filter well-known spurious artificial signals produced inside ISS.

The advantages of using EGLE device are:

(i) high-accuracy measurements;

(ii) small dimensions and mass; 


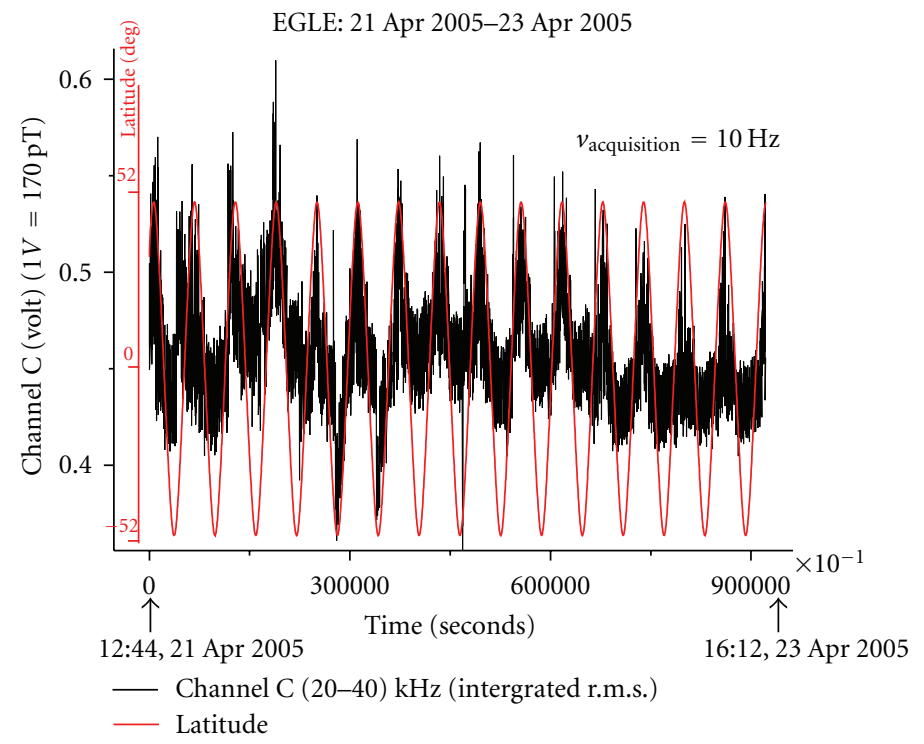

FIGURE 7: An example of magnetic data in the frequency band (20-40) kHz, recorded by the EGLE instrument on board the ISS during the period of the mission (15 April-25 April 2005). Superimposed to the signal is shown the latitude variation of the ISS.
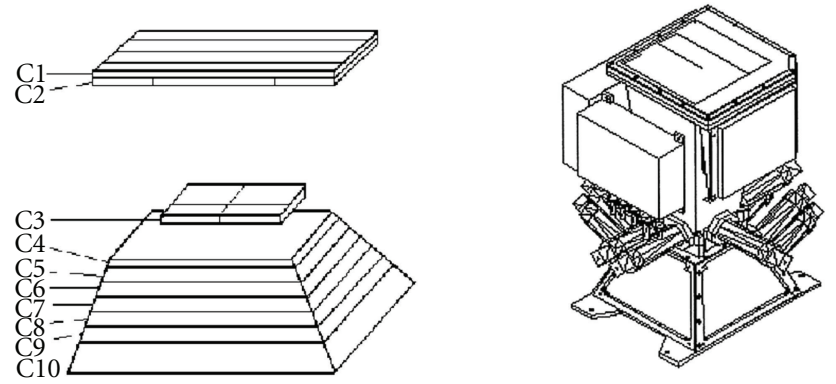

C1-C3: Trigger coincidence scintillation telescope

C4-C10: Scintillation calorimeter

C11-C12: Scintillation anticoincidence detectors

FIgURE 8: ARINA space instrument layout.

(iii) low power consumption;

(iv) data acquisition via 1-Wire technology;

(v) a standard ISS power supply of the device.

The peculiar characteristic of the 1-Wire technology prompted us to use it in the EGLE experiment to test its possible application in satellite EM measurements where the necessity to hold magnetic sensors far from the satellite body by expanding booms is an important factor for magnetic cleanness (see architecture of electric and magnetic probes in the ESPERIA payload). In fact, the use of 1Wire technology can strongly reduce the numbers of wires necessary to connect many remote magnetic and electric probes (necessary in these types of investigations) with the central electronic unit located in the satellite body.

Figure 5 depicts the LAZIO-EGLE installation inside the PIRS section of the ISS. As can be seen, MEB (left), EGLEMB (front), and EGLE-MH (right) are fixed by Velcro tags to the ISS wall. The characteristic frequency response of the
EGLE probe is reported in Figure 6. An example of data recorded on board ISS is shown in Figure 7. As it can be seen, part of the ULF frequency band can also be detected by this sensor. This is an unusual characteristic for a searchcoil probe and characterizes EGLE as an original broad-band magnetometer, which in a few satellite applications can allow a significant mass reduction by avoiding the use of flux-gate sensors.

5.2. The ARINA Particle Experiment on Board a LEO Satellite. The ARINA experiment consists of a proton-electron telescope to be installed on board the polar LEO Russian satellite RESURS-DK1 within the PAMELA mission. The orbit is elliptic, with an altitude ranging from 300 to $600 \mathrm{~km}$ and an inclination of 70.4 degree. The duration of the mission will be $\geq 3$ years. The scientific objective of the experiment is to detect fluxes of high-energy charged particles $(3 \div 100 \mathrm{MeV})$, from the inner radiation belt and to correlate them with seismic activity.

The main features of the ARINA instrument are reported in Figure 8. As can be seen from this figure, the instrument consists of a set of scintillation detectors $\mathrm{C} 1-\mathrm{C} 12$ made on the basis of polystyrene, which are viewed by photomultipliers (PMTs), the event recording system, the data acquisition and processing system (DAPS), the power supply system (PSS), and the command unit (CU). Detectors $\mathrm{C} 1-\mathrm{C} 12$ are functionally combined into three systems: the hodoscopic trigger system HTS (detectors C1-C3), the scintillation calorimeter SC (detectors C4-C9), and the anticoincidence system ACS (detectors C10-C12). Each of the detectors C1 and $\mathrm{C} 2$ consists of four strips directed perpendicularly and positioned just one under another. Detector C3 is situated below detectors $\mathrm{C} 1$ and $\mathrm{C} 2$ and has a mosaic structure (six elements). Each mosaic element is viewed by its own PMT. This type of assembly enables the angle of incident 
particle to be determined. The geometry and dimensions of detectors $\mathrm{C} 1-\mathrm{C} 3$ define the instrument aperture and the geometric factor. The scintillation calorimeter can comprise the detector C3 in addition to another set of detectors, C4C9. It provides the separation of the protons and electrons and enables the particle energy to be measured by the number of detectors, passed by the particle up to its stop; that is, it is used the range of the particle in the stack of detectors. The ACS consists of the detector C10 and lateral detectors $\mathrm{C} 11$ and $\mathrm{C} 12$, and it is needed to exclude the particles moving in the opposite direction (from the bottom to upward) from being recorded as well as all directions beyond the aperture.

\section{Conclusion}

In this paper, we aimed at giving a contribution to earthquake precursor studies. At this purpose, ground and space observations and modeling have been presented together with specific space projects. In particular, we have clarified different methodological aspects on damage prevention and prediction approaches used to defend society from such destructive events as earthquakes and provided a short summary of the scientific background of ground and space observations on earthquake precursors together with relative first theoretical interpretations. Also a possible first empirical approach to deterministic earthquake prediction based on medium-term and short-term ground and space precursory phenomena has been given. The latter consists of EM emissions radiated from the Earth's surface and produced as a consequence of earthquake preparation and occurrence, or by human activities. They demonstrated to cause ionospheric perturbations that are detectable by LEO satellites. Within this framework, we have described the ESPERIA satellite project designed for detecting seismoassociated effects in the topside ionosphere and first ESPERIA instruments (LAZIO-EGLE and ARINA), which have been tested in space. But a field mapping of the topside ionosphere also demonstrated to be an important factor to contribute in defining both the IGRF and IRI magnetic and ionospheric models, as well as the monitoring of TLE and TGF tropospheric phenomena that have recently assumed a relevant importance. An IUGG resolution of 2007 in support of ESPERIA and, more generally, of an ionospheric mission with all the above elements as scientific objectives, triggered us in proposing the AUSONIA space project.

\section{Acknowledgment}

The authors declare that they do not have any relation with all commercial devices mentioned in our paper, and that there is no conflict of interest for any of them.

\section{References}

[1] Japanese National Police Agency, Countermeasures for the Great East Japan Earthquake, http://www.npa.go.jp/archive/ keibi/biki/higaijokyo_e.pdf.

[2] V. Sgrigna, A. Buzzi, L. Conti, P. Picozza, C. Stagni, and D. Zilpimiani, "Seismo-induced effects in the near-earth space: combined ground and space investigations as a contribution to earthquake prediction," Tectonophysics, vol. 431, no. 1-4, pp. 153-171, 2007.

[3] V. I. Keilis-Borok, "Intermediate-term earthquake prediction," Proceedings of the National Academy of Sciences of the United States of America, vol. 93, no. 9, pp. 3748-3755, 1996.

[4] V. I. Keilis Borok and A. Soloviev, Non Linear Dynamics of the Lithosphere and Earthquake Prediction, Springer, Berlin, Germany, 2003.

[5] A. Peresan, V. Kossobokov, L. Romashkova, and G. F. Panza, "Intermediate-term middle-range earthquake predictions in Italy: a review," Earth-Science Reviews, vol. 69, no. 1-2, pp. 97-132, 2005.

[6] A. Tzanis and F. Vallianatos, "Distributed power-law seismicity changes and crustal deformation in the SW Hellenic ARC," Natural Hazards and Earth System Science, vol. 3, no. 3-4, pp. 179-195, 2003.

[7] V. Sgrigna, R. Console, L. Conti et al., "Preseismic natural emissions from the Earth's surface and their effects in the near earth space, A project for monitoring earthquakes from Space," American Geophysical Union, vol. 83, no. 19, article S356, 2002, abstract no. T22B-10.

[8] V. Sgrigna, L. Carota, L. Conti et al., "Correlations between earthquakes and anomalous particle bursts from SAMPEX/PET satellite observations," Journal of Atmospheric and Solar-Terrestrial Physics, vol. 67, no. 15, pp. 1448-1462, 2005.

[9] S. A. Pulinets, "Space technologies for short-term earthquake warning," Advances in Space Research, vol. 37, no. 4, pp. 643652, 2006.

[10] M. Long, A. Lorenz, G. Rodgers et al., "A cubesat derived design for a unique academic research mission in earthquake signature detection," in Proceedings of the 16th Annual/USU Conference on Small Satellites, pp. 1-17, Logan, Utah, USA, August 2002.

[11] M. Parrot, “The micro-satellite DEMETER," Journal of Geodynamics, vol. 33, no. 4-5, pp. 535-541, 2002.

[12] V. Sgrigna, "(Principal Investigator), esperia science team, ESPERIA phase a report,” Italian Space Agency (ASI), Program for Scientific Missions dedicated to Earth Sciences, Rome, Italy, 2001.

[13] V. Sgrigna, A. Buzzi, L. Conti, P. Picozza, C. Stagni, and D. Zilpimiani, "The ESPERIA satellite project for detecting seismic-associated effects in the topside ionosphere. First instrumental tests in space," Earth Planets and Space, vol. 60, pp. 463-475, 2009.

[14] V. Sgrigna, the Ausonia Collaboration, The AUSONIA space project, Proposal submitted to the Italian Space Agency, 2008.

[15] P. Picozza, (PAMELA/ARINA collaboration), The PAMELA Mission, 2003, http://wizard.roma2.infn.it/pamela/index .htm.

[16] V. Sgrigna and V. Malvezzi, "Preseismic creep strains revealed by ground tilt measurements in central Italy on the occasion of the 1997 Umbria-Marche Apennines earthquake sequence," Pure and Applied Geophysics, vol. 160, no. 8, pp. 1493-1515, 2003.

[17] V. Sgrigna, C. D’ambrosio, and T. B. Yanovskaya, "Numerical modeling of preseismic slow movements of crustal blocks caused by quasi-horizontal tectonic forces," Physics of the Earth and Planetary Interiors, vol. 129, pp. 313-324, 2002.

[18] L. Conti, A. Buzzi, and A. M. Galper, "Influence of the seismic activity on the inner Van Allen radiation belt," in Proceedings of the 10th Scientific Assembly of the International Association of Geomagnetism and Aeronomy (IAGA '05), p. 46, Toulose, France, July 2005, Session Division I, GA101: Monitoring 
earthquakes and volcanic activity by magnetic, electric and electromagnetic methods; IAGA2005-A-01518.

[19] V. Sgrigna, "Description and testing of ARINA and LAZIO/EGLE instruments in space within the ESPERIA mission project and the DEMETER guest investigation programme," in DEMETER Guest Investigator Workshop, Paris, France, May 2005.

[20] T. Lay and T. C. Wallace, Modern Global Seismology, Academic Press, San Diego, Calif, USA, 1995.

[21] A. M. Nur, "Dilatation, pore fluids and premonitory variation of TP/TS travel time," Bulletin of the Seismological Society of America, vol. 62, pp. 1217-1222, 1972.

[22] C. H. Scholz, "A physical interpretation of the Haicheng earthquake prediction," Nature, vol. 267, no. 5607, pp. 121124, 1977.

[23] V. I. Mjachkin, W. F. Brace, G. A. Sobolev, and J. H. Dieterich, "Two models for earthquake forerunners," Pure and Applied Geophysics PAGEOPH, vol. 113, no. 1, pp. 169-181, 1975.

[24] I. P. Dobrovolsky, S. I. Zubkov, and V. I. Miachkin, "Estimation of the size of earthquake preparation zones," Pure and Applied Geophysics PAGEOPH, vol. 117, no. 5, pp. 1025-1044, 1979.

[25] I. P. Dobrovolsky, N. I. Gershenzon, and M. B. Gokhberg, "Theory of electrokinetic effects occurring at the final stage in the preparation of a tectonic earthquake," Physics of the Earth and Planetary Interiors, vol. 57, no. 1-2, pp. 144-156, 1989.

[26] F. Bella, M. Caputo, G. Della Monica et al., "Crustal blocks and seismicity in the Central Apennines of Italy," Nuovo Cimento della Societa Italiana di Fisica C, vol. 21, no. 6, pp. 597-607, 1998.

[27] T. Rikitake, "Earthquake precursors," Bulletin of the Seismological Society of America, vol. 65, pp. 1133-1162, 1975.

[28] L. Conti, A. Cirella, V. Malvezzi, and V. Sgrigna, "A model for the propagation of preseismic electromagnetic fields through lithospheric and atmospheric media," in Proceedings of the 1st General Assembly, European Geosciences Union, p. 337, Nice, France, April 2004.

[29] R. G. Bilham, "Delays in the onset times of near-surface strain and tilt precursor to earthquakes," in Earthquake Prediction: An International Review, P. J. Simpson and P. G. Richards, Eds., pp. 411-421, Geophysical Union, Washington, DC, USA, 1981.

[30] F. Bella, P. F. Biagi, M. Caputo et al., "Very slow-moving crustal strain disturbances," Tectonophysics, vol. 179, no. 1-2, pp. 131-139, 1990.

[31] F. Bella, P. F. Biagi, M. Caputo et al., "Possible creep-related tilt precursors obtained in the Central Apennines (Italy) and in the Southern Caucasus (Georgia)," Pure and Applied Geophysics PAGEOPH, vol. 144, no. 2, pp. 277-300, 1995.

[32] S. McHugh and M. J. S. Johnston, "A review of observations and dislocation modeling of some creep-related tilt perturbations from central California," in Terrestrial and Space Techniques in earthquake Prediction, A. Vogel, Ed., pp. 181201, Vieweg and Sohn, Braunschweig, Germany, 1979.

[33] R. G. Bilham, J. Beavan, K. Evans, and K. Hurst, "Crustal deformation metrology at lamont-doherty geological observatory," Earthquake Prediction Research, vol. 3, pp. 391-411, 1985.

[34] W. Thatcher and N. Fujita, "Deformation of the mikata rhombus: strain buildup following the 1923 kanto earthquake, Central Honshu, Japan," Journal of Geophysical Research, vol. 89, pp. 2102-2106, 1984.
[35] S. Ozawa, T. Nishimura, H. Suito, T. Kobayashi, M. Tobita, and T. Imakiire, "Coseismic and postseismic slip of the 2011 magnitude-9 Tohoku-Oki earthquake," Nature, vol. 475, no. 7356, pp. 373-377, 2011.

[36] C. E. Mortensen and M. J. S. Johnston, "The nature of surface tilt along $85 \mathrm{~km}$ of the San Andreas fault-preliminary results form a 14-instrument array," Pure and Applied Geophysics PAGEOPH, vol. 113, no. 1, pp. 237-249, 1975.

[37] R. G. Bilham and R. J. Beavan, "Strains and tilts on crustal blocks," Tectonophysics, vol. 52, no. 1-4, pp. 121-138, 1979.

[38] A. Nur, H. Ron, and O. Scotti, "Fault mechanics and the kinematics of block rotations," Geology, vol. 14, no. 9, pp. 746-749, 1986.

[39] Y. Ida, "Slow-moving deformation pulses along tectonic faults," Physics of the Earth and Planetary Interiors, vol. 9, no. 4, pp. 328-337, 1974.

[40] A. K. Pevnev, "Earthquake prediction: geodetic aspects of the problem," Izvestija Akademija Nauk SSSR. Fizika Zemli, vol. 12, pp. 88-98, 1988.

[41] A. K. Pevnev, "Deterministic geodetic prediction of preparation areas of strong crustal earthquakes," Earthquake Prediction, vol. 11, pp. 11-23, 1989.

[42] F. Bella, R. Bella, P. F. Biagi, A. Ermini, and V. Sgrigna, "Possible precursory tilts preceding some earthquakes $(3.0 \leq$ $M \leq 3.8$ ) occurred in Central Italy between February 1981 and June 1983," Earthquake Prediction Research, vol. 4, pp. 147-154, 1986.

[43] F. Bella, P. F. Biagi, M. Caputo, G. Della Monica, A. Ermini, and V. Sgrigna, "Ground Tilt anomalies accompanying the main earthquakes occurred in the central apennines (Italy) during the period 1986-1989," Il Nuovo Cimento C, vol. 16, no. 4, pp. 393-406, 1993.

[44] R. J. Geller, "Debate on VAN," Geophysical Research Letters, vol. 23, no. 11, 1996.

[45] F. Salvini, "Block tectonics in thin-skin style-deformed regions: examples from structural data in the central apennines," Annali di Geofisica, vol. 36, pp. 97-109, 1993.

[46] F. Bella, P. F. Biagi, A. Ermini, V. Sgrigna, and P. Manjgaladze, "Possible propagation of tilt and strain anomalies: velocity and other characteristics," Earthquake Prediction Research, vol. 4, pp. 195-209, 1986.

[47] A. M. Gabrielov, T. A. Levshina, and I. M. Rotwain, "Block model of earthquake sequence," Physics of the Earth and Planetary Interiors, vol. 61, no. 1-2, pp. 18-28, 1990.

[48] V. P. Pustovetov and A. B. Malyshev, "Space-time correlation of earthquakes and high-energy particle flux variations in the inner radiation belt," Cosmic Research, vol. 31, pp. 84-90, 1993.

[49] E. A. Ginzburg, A. B. Malishev, I. P. Proshkina, and V. P. Pustovetov, "Correlation of strong earthquakes with radiation belt particle flux variations," Geomagn Aeronomy, vol. 34, pp. 315-320, 1994.

[50] A. M. Galper, S. V. Koldashov, and S. A. Voronov, "High energy particle flux variations as earthquake predictors," Advances in Space Research, vol. 15, no. 11, pp. 131-134, 1995.

[51] S. Y. Aleksandrin, A. M. Galper, L. A. Grishantzeva et al., "High-energy charged particle bursts in the near-Earth space as earthquake precursors," Annales Geophysicae, vol. 21, no. 2, pp. 597-602, 2003.

[52] M. Walt, Introduction to Geomagnetically Trapped Radiation, Cambridge University Press, 1994.

[53] M. E. Aleshina, S. A. Voronov, A. M. Galper et al., "Correlation between earthquake epicenters and regions of 
high-energy particle precipitations from the radiation belt," Cosmic Research, vol. 30, no. 1, pp. 79-83, 1992.

[54] M. Parrot, J. Achache, J. J. Berthelier et al., "High-frequency seismo-electromagnetic effects," Physics of the Earth and Planetary Interiors, vol. 77, no. 1-2, pp. 65-83, 1993.

[55] O. A. Molchanov and M. Hayakawa, "On the generation mechanism of ULF seismogenic electromagnetic emissions," Physics of the Earth and Planetary Interiors, vol. 105, no. 3-4, pp. 201-210, 1998.

[56] O. A. Molchanov and M. Hayakawa, "Subionospheric VLF signal perturbations possibly related to earthquakes," Journal of Geophysical Research, vol. 103, pp. 17489-17504, 1998.

[57] Y. J. Chuo, J. Y. Liu, S. A. Pulinets, and Y. I. Chen, "The ionospheric perturbations prior to the Chi-Chi and ChiaYi earthquakes," Journal of Geodynamics, vol. 33, no. 4-5, pp. 509-517, 2002.

[58] V. Sgrigna, F. Altamura, S. Ascani et al., "First data from the EGLE experiment onboard the ISS," Microgravity Science and Technology, vol. 19, no. 5-6, pp. 70-74, 2007.

[59] M. J. S. Johnston and R. J. Mueller, "Seismomagnetic observation during the 8 July 1986 magnitude 5.9 North Palm Springs earthquake," Science, vol. 237, no. 4819, pp. 1201-1203, 1987.

[60] P. Varotsos, K. Alexopoulos, M. Lazaridou-Varotsou, and T. Nagao, "Earthquake predictions issued in Greece by seismic electric signals since February 6, 1990," Tectonophysics, vol. 224, no. 1-3, pp. 269-288, 1993.

[61] K. Nomikos, F. Vallianatos, I. Kaliakatsos, E. Sideris, and M. Bakatsakis, "The latest aspects of telluric and electromagnetic variations associated with shallow and intermediate depth earthquakes in the South Aegean," Annali di Geofisica, vol. 40, no. 2, pp. 361-374, 1997.

[62] A. B. Draganov, U. S. Inan, and Y. N. Taranenko, "ULF magnetic signatures at the Earth surface due to ground water flow: a possible precursor to earthquakes," Geophysical Research Letters, vol. 18, no. 6, pp. 1127-1130, 1991.

[63] Y. Bernabé, "Streaming potential in heterogeneous networks," Journal of Geophysical Research B, vol. 103, no. 9, pp. 20827-20841, 1998.

[64] J. R. Bishop, "Piezoelectric effects in quartz-rich rocks," Tectonophysics, vol. 77, no. 3-4, pp. 297-321, 1981.

[65] P. Varotsos, N. Sarlis, M. Lazaridou, and P. Kapiris, "Transmission of stress induced electric signals in dielectric media," Journal of Applied Physics, vol. 83, no. 1, pp. 60-70, 1998.

[66] F. Freund, "Charge generation and propagation in igneous rocks," Journal of Geodynamics, vol. 33, no. 4-5, pp. 543-570, 2002.

[67] I. Stavrakas, C. Anastasiadis, D. Triantis, and F. Vallianatos, "Piezo stimulated currents in marble samples: precursory and concurrent-with-failure signals," Natural Hazards and Earth System Science, vol. 3, no. 3-4, pp. 243-247, 2003.

[68] Y. A. Kopytenko, T. G. Matiashvili, P. M. Voronov, E. A. Kopytenko, and O. A. Molchanov, "Detection of ultra-lowfrequency emissions connected with the Spitak earthquake and its aftershock activity, based on geomagnetic pulsations data at Dusheti and Vardzia observatories," Physics of the Earth and Planetary Interiors, vol. 77, no. 1-2, pp. 85-95, 1993.

[69] A. C. Fraser-Smith, P. R. McGill, R. A. Helliwell, and O. G. Villard, "Ultra low frequency magnetic field measurements in southern California during the Northridge Earthquake of 17 January 1994," Geophysical Research Letters, vol. 21, no. 20, pp. 2195-2198, 1994.
[70] V. S. Ismaguilov, Y. A. Kopytenko, K. Hattori, P. M. Voronov, O. A. Molchanov, and M. Hayakawa, "ULF magnetic emissions connected with under sea bottom earthquakes," Natural Hazards and Earth System Sciences, vol. 1, pp. 23-31, 2001.

[71] K. Ohta, K. Umeda, N. Watanabe, and M. Hayakawa, "ULF/ELF emissions observed in Japan, possibly associated with the Chi-Chi earthquake in Taiwan," Natural Hazards and Earth System Sciences, vol. 1, pp. 37-42, 2001.

[72] J. W. Warwick, C. Stoker, and T. R. Meyer, "Radio emission associated with rock fracture: possible application to the great Chilean Earthquake of May 22, 1960," Journal of Geophysical Research, vol. 87, no. 4, pp. 2851-2859, 1982.

[73] K. Oike and T. Ogawa, "Electromagnetic radiations from shallow earthquakes observed in the LF range," Journal of Geomagnetism \& Geoelectricity, vol. 38, no. 10, pp. 10311040, 1986.

[74] M. J. S. Johnston, "Review of electric and magnetic fields accompanying seismic and volcanic activity," Surveys in Geophysics, vol. 18, no. 5, pp. 441-475, 1997.

[75] S. Uyeda, K. S. Al-Damegh, E. Dologlou, and T. Nagao, "Some relationship between VAN seismic electric signals (SES) and earthquake parameters," Tectonophysics, vol. 304, no. 1-2, pp. 41-55, 1999.

[76] K. Eftaxias, P. Kapiris, J. Polygiannakis et al., "Experience of short term earthquake precursors with VLF-VHF electromagnetic emissions," Natural Hazards and Earth System Science, vol. 3, no. 3-4, pp. 217-228, 2003.

[77] F. Vallianatos, D. Triantis, A. Tzanis, C. Anastasiadis, and I. Stavrakas, "Electric earthquake precursors: from laboratory results to field observations," Physics and Chemistry of the Earth, vol. 29, no. 4-9, pp. 339-351, 2004.

[78] A. Nardi and M. Caputo, "Perspective electric earthquake precursors observed in the Apennines," in Proceedings of the 8th Workshop on Non Linear Dynamics and Earthquake Prediction, ICTP, October 2005.

[79] A. Nardi and M. Caputo, "Perspective electric earthquake precursors observed in the Apennines," Bollettino di Geofisica Teorica ed Applicata, vol. 47, pp. 3-12, 2006.

[80] S. K. Park, M. J. S. Johnston, T. R. Madden, F. D. Morgan, and H. F. Morrison, "Electromagnetic precursors to earthquakes in the ulf band: a review of observations and mechanisms," Reviews of Geophysics, vol. 31, no. 2, pp. 117-132, 1993.

[81] M. Merzer and S. L. Klemperer, "Modeling low-frequency magnetic-field precursors to the Loma Prieta earthquake with a precursory increase in fault-zone conductivity," Pure and Applied Geophysics, vol. 150, no. 2, pp. 217-248, 1997.

[82] V. Surkov, "ULF electromagnetic perturbations resulting from the fracture and dilatancy in the earthquake preparation zone," in Atmospheric and Ionospheric Electromagnetic Phenomena Associated with Earthquakes, M. Hayakawa, Ed., pp. 371-382, TERRAPUB, Tokyo, Japan, 1999.

[83] M. Hayakawa, Y. Kopytenko, N. Smirnova, V. Troyan, and T. Peterson, "Monitoring ULF magnetic disturbances and schemes for recognizing earthquake precursors," Physics and Chemistry of the Earth, Part A, vol. 25, no. 3, pp. 263-269, 2000.

[84] F. Freund, "On the electrical conductivity structure of the stable continental crust," Journal of Geodynamics, vol. 35, no. 3, pp. 353-388, 2003.

[85] G. Areshidze, F. Bella, P. F. Biagi et al., "Anomalies in geophysical and geochemical parameters revealed on the occasion of the Paravani $(M=5.6)$ and Spitak $(M=6.9)$ 
earthquakes (Caucasus)," Tectonophysics, vol. 202, no. 1, pp. 23-41, 1992.

[86] Z. Guo, B. Liu, and Y. Wang, "Mechanism of electromagnetic emissions associated with microscopic and macroscopic cracking in rocks," in Electromagnetic Phenomena Related to Earthquake Prediction, M. Hayakawa, Ed., pp. 523-529, TERRAPUB, Tokyo, Japan, 1994.

[87] F. T. Freund, A. Takeuchi, and B. W. S. Lau, "Electric currents streaming out of stressed igneous rocks-a step towards understanding pre-earthquake low frequency EM emissions," Physics and Chemistry of the Earth, vol. 31, no. 4-9, pp. 389396, 2006.

[88] K. Eftaxias, V. Sgrigna, and T. Chelidze, "Mechanical and electromagnetic phenomena accompanying pre-seismic deformation: from laboratory to geophysical scale," Tectonophysics, vol. 431, no. 1-4, pp. 1-5, 2007.

[89] O. A. Molchanov, O. A. Mazhaeva, A. N. Golyavin, and M. Hayakawa, "Observation by the Intercosmos-24 satellite of ELF-VLF electromagnetic emissions associated with earthquakes," Annales Geophysicae, vol. 11, pp. 431-440, 1993.

[90] C. J. Rodger, R. L. Dowden, and N. R. Thomson, "Observations of electromagnetic activity associated with earthquakes by low-altitude satellites," in Atmospheric and Ionospheric Electromagnetic Phenomena Associated with Earthquakes, M. Hayakawa, Ed., pp. 697-710, TERRAPUB, Tokyo, Japan, 1999.

[91] M. B. Gokhberg, V. A. Morgounov, and E. L. Aronov, "On the high frequency electromagnetic radiation during seismic activity," Dokladi Akademii Nauk USSR, vol. 248, pp. 10771081, 1979.

[92] V. I. Larkina, V. V. Migulin, O. A. Molchanov, I. P. Kharkov, A. S. Inchin, and V. V. Schvetsova, "Some statistical results on very low frequency radiowave emissions in the upper ionosphere over earthquake zones," Physics of the Earth and Planetary Interiors, vol. 57, pp. 100-109, 1989.

[93] M. Parrot and M. M. Mogilevsky, "VLF emissions associated with earthquakes and observed in the ionosphere and the magnetosphere," Physics of the Earth and Planetary Interiors, vol. 57, no. 1-2, pp. 86-99, 1989.

[94] S. V. Bilichenko, F. S. Iljin, E. F. Kim et al., "ULF response of the ionosphere for earthquake preparation processes," Doklady Akademii Nauk USSR, vol. 311, pp. 1077-1080, 1990.

[95] O. N. Serebryakova, S. V. Bilichenko, V. M. Chmyrev et al., "Electromagnetic ELF radiation from earthquake regions as observed by low-altitude satellite," Geophysical Research Letters, vol. 19, pp. 91-94, 1992.

[96] V. M. Chmyrev, N. V. Isaev, O. N. Serebryakova, V. M. Sorokin, and Y. P. Sobolev, "Small-scale plasma inhomogeneities and correlated ELF emissions in the ionosphere over an earthquake region," Journal of Atmospheric and SolarTerrestrial Physics, vol. 59, no. 9, pp. 967-974, 1997.

[97] C. C. Lee, J. Y. Liu, C. J. Pan, and K. Igarashi, "The heights of sporadic-E layer simultaneously observed by the VHF radar and ionosondes in Chung-Li," Geophysical Research Letters, vol. 27, no. 5, pp. 641-644, 2000.

[98] S. A. Pulinets, K. A. Boyarchuk, V. V. Hegai, V. P. Kim, and A. M. Lomonosov, "Quasielectrostatic model of atmosphere-thermosphere-ionosphere coupling," Advances in Space Research, vol. 26, no. 8, pp. 1209-1218, 2000.

[99] M. Hayakawa, O. A. Molchanov, and A. P. Nikolaenko, "Model variations in atmospheric radio noise caused by preseismic modifications of tropospheric conductivity profile," in Seismo Electromagnetics: Lithosphere-AtmosphereIonosphere Coupling, M. Hayakawa and O. A. Molchanov, Eds., pp. 349-352, TERRAPUB, Tokyo, Japan, 2002.

[100] A. Buzzi, L. Conti, A. M. Galper et al., "Sismoelectromagnetic emissions," in Proceedings of the NATO Advances Study. Institute on 'Sprites, Elves and Intense Lightning Discharges', M. Fullekrug, E. A. Mareev, and M. J. Rycroft, Eds., vol. 225 of NATO Science Series II: Mathematics, Physics and Chemistry, pp. 388-389, Springer, 2006.

[101] M. Parrot, "Statistical study of ELF/VLF emissions recorded by a low-altitude satellite during seismic events," Journal of Geophysical Research, vol. 99, pp. 23339-23347, 1994.

[102] M. A. Fenoglio, M. J. S. Johnston, and J. D. Byerlee, "Magnetic and electric fields associated with changes in high pore pressure in fault zones: application to the Loma Prieta ULF emissions," Journal of Geophysical Research, vol. 100, no. 7, pp. 12-958, 1995.

[103] O. A. Molchanov, M. Hayakawa, and V. A. Rafalsky, "Penetration characteristics of electromagnetic emissions from an underground seismic source into the atmosphere, ionosphere and magnetosphere," Journal of Geophysical Research, vol. 100, pp. 1691-1712, 1995.

[104] R. Teisseyre, "Generation of electric field in an earthquake preparation zone," Annali di Geofisica, vol. 40, no. 2, pp. 297304, 1997.

[105] V. V. Grimalsky, I. A. Kremenetsky, and Y. G. Rapoport, "Excitation of EMW in the lithosphere and propagation into magnetosphere," in Atmospheric and Ionospheric Electromagnetic Phenomena Associated with Earthquakes, M. Hayakawa, Ed., pp. 777-787, TERRAPUB, Tokyo, Japan, 1999.

[106] F. Vallianatos and A. Tzanis, "A model for the generation of precursory electric and magnetic fields associated with the deformation rate of the earthquake focus," in Atmospheric and Ionospheric Electromagnetic Phenomena Associated with Earthquakes, M. Hayakawa, Ed., pp. 287-305, TERRAPUB, Tokyo, Japan, 1999.

[107] V. M. Sorokin, V. M. Chmyrev, and A. K. Yaschenko, "Electrodynamic model of the lower atmosphere and the ionosphere coupling," Journal of Atmospheric and SolarTerrestrial Physics, vol. 63, pp. 1681-1691, 2001.

[108] N. Gershenzon and G. Bambakidis, "Modeling of seismoelectromagnetic phenomena," Russian Journal of Earth Sciences, vol. 3, pp. 247-275, 2001.

[109] Y. Fujinawa, T. Matsumoto, and K. Takahashi, "Modeling confined pressure changes inducing anomalous electromagnetic fields related with earthquakes," Journal of Applied Geophysics, vol. 49, no. 1-2, pp. 101-110, 2002.

[110] J. Y. Liu, Y. I. Chen, Y. J. Chuo, and C. S. Chen, "A statistical investigation of preearthquake ionospheric anomaly," Journal of Geophysical Research A, vol. 111, no. 5, Article ID A05304, 2006.

[111] K. Heki, "Ionospheric electron enhancement preceding the 2011 Tohoku-Oki earthquake," Geophysical Research Letters, vol. 8, Article ID L17312, 5 pages, 2011.

[112] H. Tsuji, Y. Hatanaka, T. Sagiya, and M. Hashimoto, "Coseismic crustal deformation from the 1994 Hokkaido-Toho-Oki earthquake monitored by a nationwide continuous GPS array in Japan," Geophysical Research Letters, vol. 22, no. 13, pp. 1669-1672, 1995.

[113] E. Blanc, "Observations in the upper atmosphere of infrasonic waves from natural or artificial sources: a summary," Annales Geophysicae, vol. 3, no. 6, pp. 673-688, 1985. 
[114] Y. Zaslavski, M. Parrot, and E. Blanc, "Analysis of TEC measurements above active seismic regions," Physics of the Earth and Planetary Interiors, vol. 105, pp. 219-228, 1998.

[115] A. M. Galper, V. B. Dimitrenko, N. V. Nikitina, V. M. Grachev, and S. E. Ulin, "Interrelation between high-energy charged particle fluxes in the radiation belt and seismicity of the earth," Cosmic Research, vol. 27, article 789, 1989.

[116] S. A. Voronov, A. M. Galper, S. V. Koldashov et al., "Increases in high energy charged particle fluxes near the South Atlantic magnetic anomaly and the seismicity of the earth," Cosmic Research, vol. 28, pp. 789-791, 1990.

[117] Y. I. Galperin, V. A. Gladyshev, N. V. Jordjio, and V. I. Larkina, "Precipitation of high-energy captured particles in the magnetosphere above the epicenter of an incipient earthquake," Cosmic Research, vol. 30, pp. 89-106, 1992.

[118] A. Buzzi, M. Parrot, and J. A. Sauvaud, "Precipitation of particles by intense electromagnetic harmonic waves during magnetic storms," in Proceedings of the International Demeter Workshop, Toulouse, France, June 2006.

[119] V. V. Krechetov, "Cerenkov radiation of protons in the magnetosphere as a source of VLF waves preceding an earthquake," Geomagnetism and Aeronomy, vol. 35, no. 5, pp. 688-691, 1996.

[120] M. Hayakawa and H. Sato, "Ionospheric perturbations associated with earthquakes, as detected by sub-ionospheric VLF propagation," in Electromagnetic Phenomena Related to Earthquake Prediction, M. Hayakawa and Y. Fujinawa, Eds., pp. 391-397, TERRAPUB, Tokyo, Japan, 1994.

[121] V. A. Morgounov, T. Ondoh, and S. Nagai, "Anomalous variation of VLF signals associated with strong earthquakes $M \geq$ 7.0," in Electromagnetic Phenomena Related to Earthquake Prediction, M. Hayakawa and Y. Fujinawa, Eds., pp. 409-428, TERRAPUB, Tokyo, Japan, 1994.

[122] I. Gufeld, G. Gusev, and O. Pokhotelov, "Is the prediction of earthquake dates possible by the VLF radiowave monitoring method?" in Electromagnetic Phenomena Related to Earthquake Prediction, M. Hayakawa and Y. Fujinawa, Eds., pp. 381-389, TERRAPUB, Tokyo, Japan, 1994.

[123] H. Fujiwara, M. Kamogawa, M. Ikeda et al., "Atmospheric anomalies observed during earthquake occurrences," Geophysical Research Letters, vol. 31, Article ID L17110, 4 pages, 2004. 

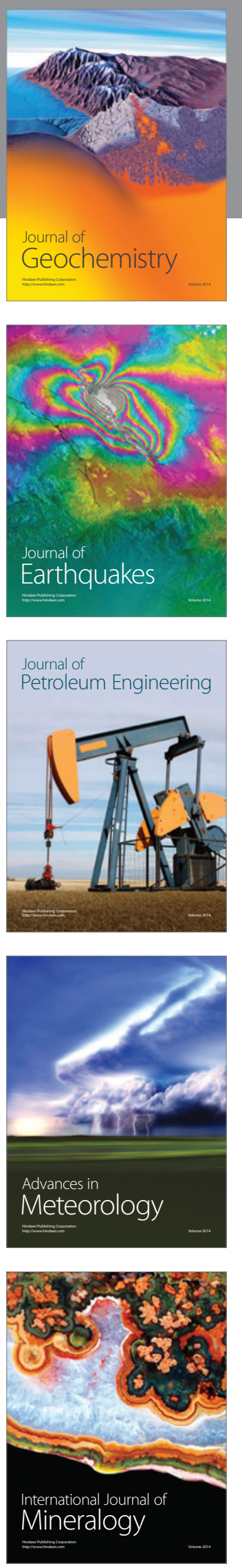
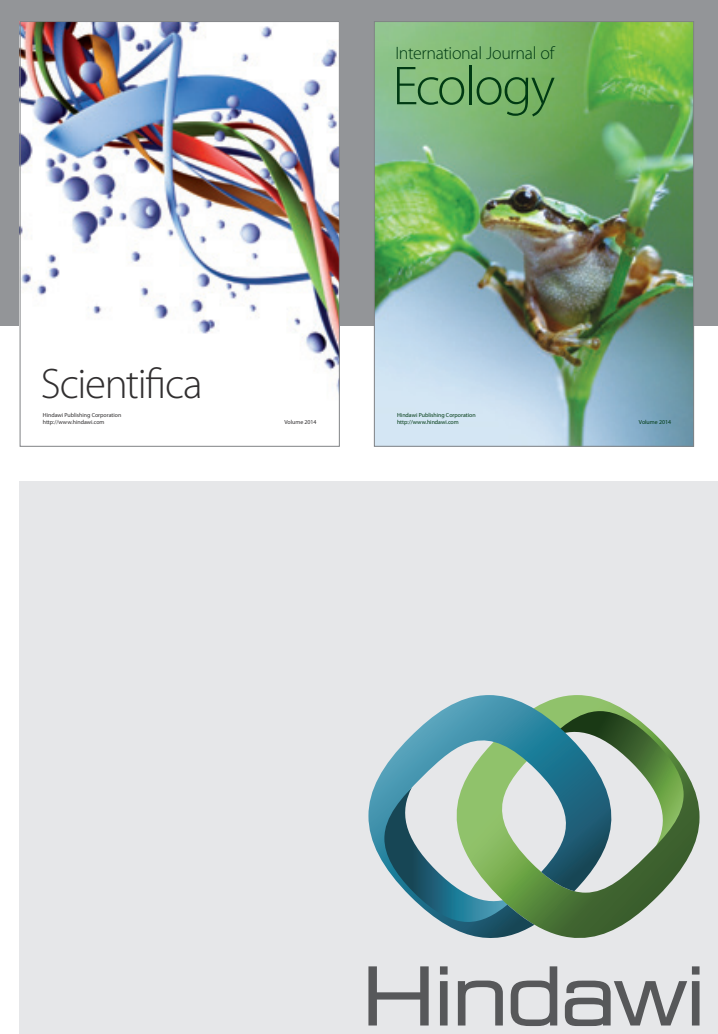

Submit your manuscripts at http://www.hindawi.com
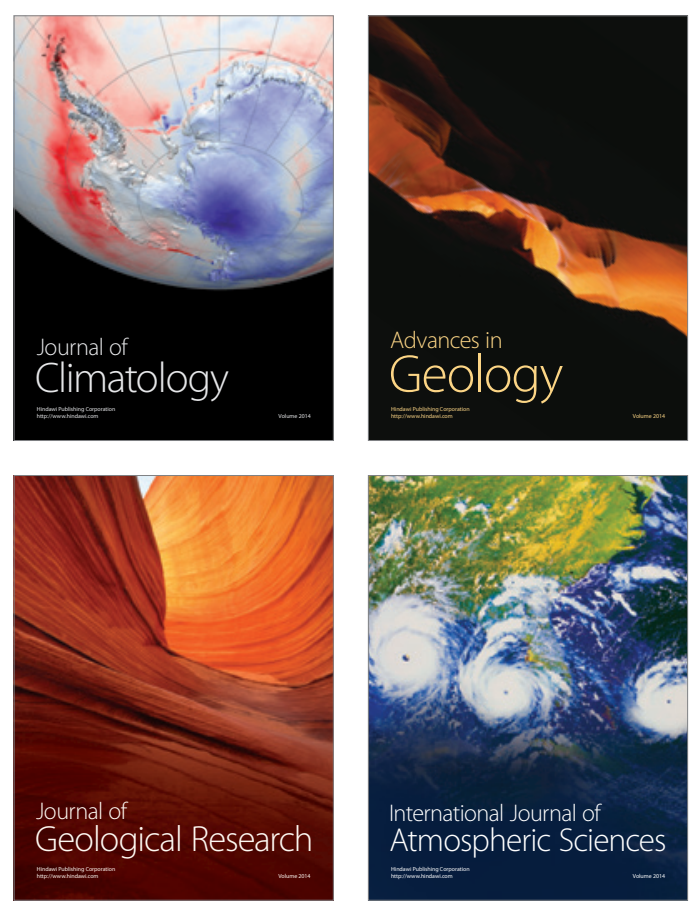
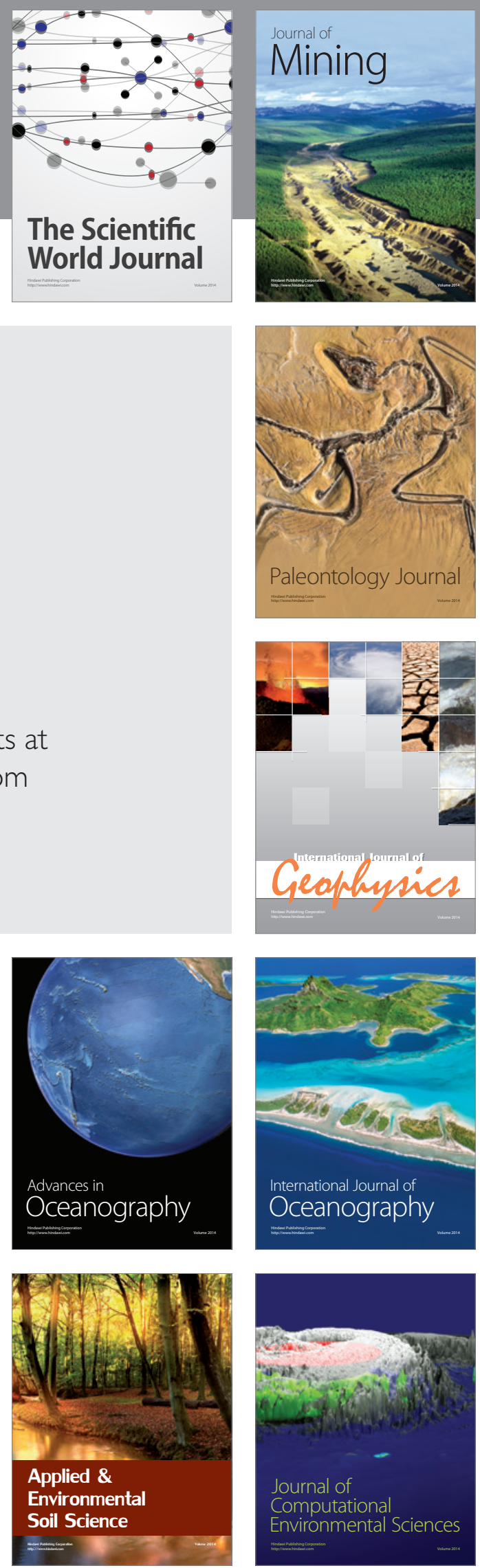